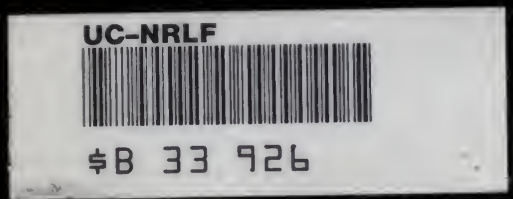



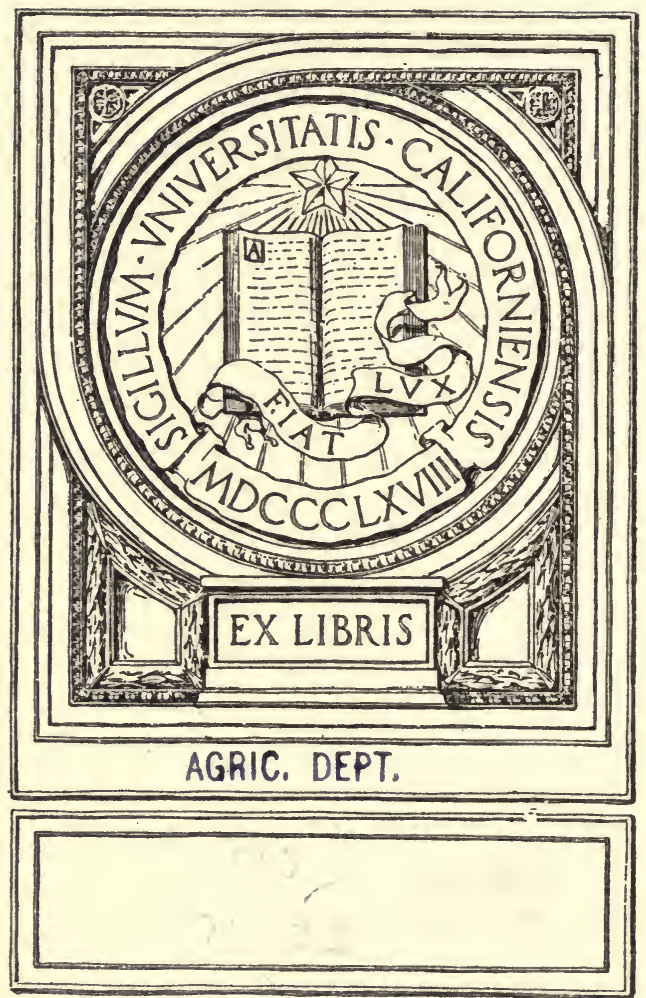




Fifth Edition, 10,000, 1908.

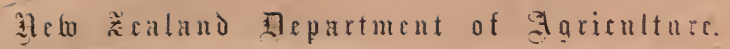

JOHN D. RITCHIE, Secretary.

\section{POULTRY AND EGGS}

MARKET AND EXPORT.

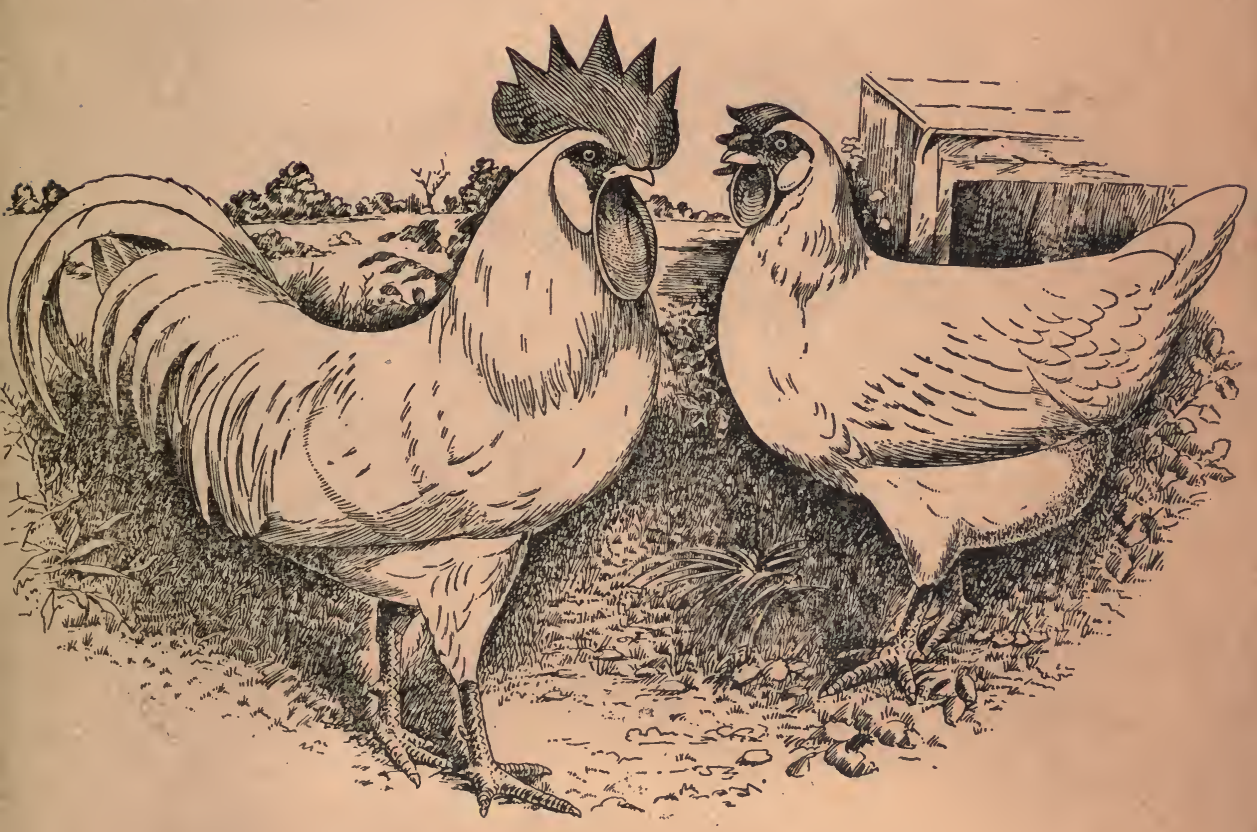

By D. D. HYDE, Chief Poultry Expert.

The Hon. ROBERT McNAB, Minister for Agriculture.

WELLINGTON, N.Z.

13Y AUTHORITY : JOHN MACKAY, GOVERNMENT PRINTER.

1908 . 


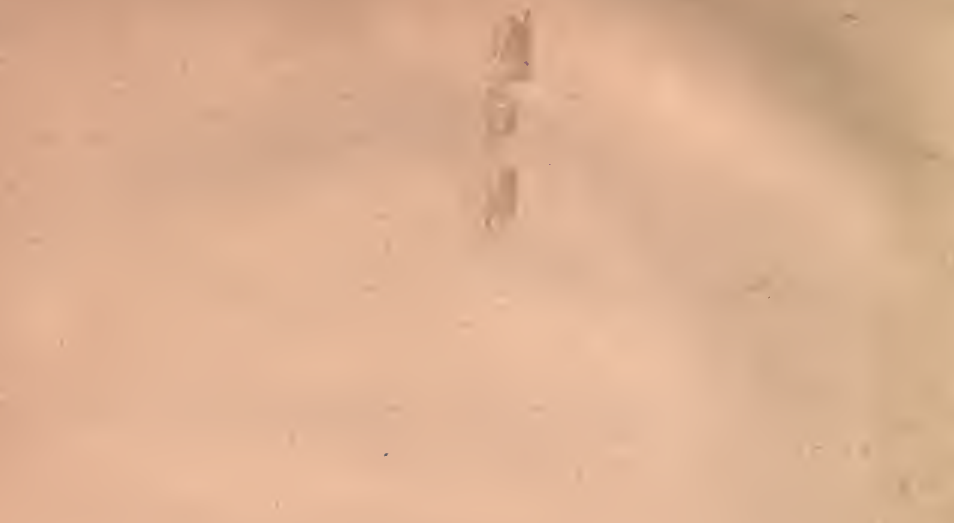




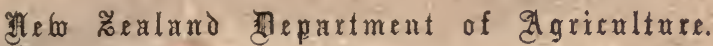
JOHN D. RITCHIE, Secretary.

\section{POULTRY AND EGGS non}

\section{MARKET AND EXPORT.}

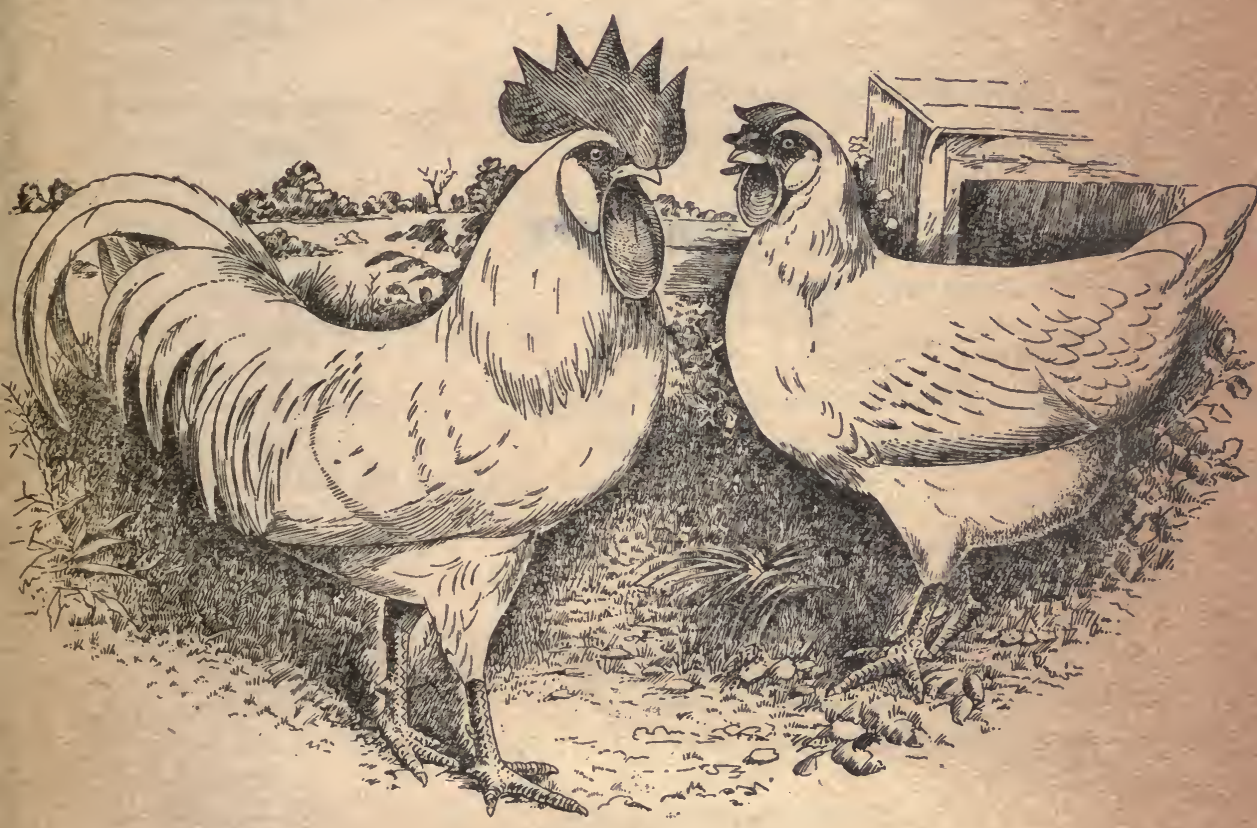

By D. D. HYDE, Chief Poultry Expert.

The Hon. ROBERT McNAB, Minister for Agriculture.

WELLINGTON, '̀.

BY AUTHORITY : JOHN MACKAY, GOVERNMENT PRINTER. 
AGRIC. DEPT

Eale Wikn

Levis, bipso

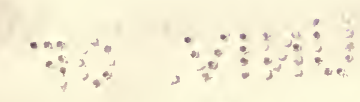

$\therefore$ 


\section{INDEX.}

Air-cell in eggs ... Pag

$\begin{array}{lllll}\text { Apoplexy } & \text {.. } & \text {.. } & \text {.. } & 45\end{array}$

Artificial incubation $\quad$.. $\quad$.. 18

$\begin{array}{lllll}\text { Best lajers } \quad . . & \text {. } & \text {.. } & 27\end{array}$

Brooders at Moumahaki and Burn-

ham .. $\quad$.. $\quad$.. $\quad$.. 22,23

$\begin{array}{llll}\text { Brooding chicks.. } & \text {.. } & \text {.. } & 20\end{array}$

$\begin{array}{llll}\text { Calway brooder .. } & \text {.. } & \text {.. } & 24\end{array}$

$\begin{array}{llll}\text { Causes of disease } & \text {. } & \text {.. } & 42\end{array}$

$\begin{array}{lllll}\text { Cholera } & \text {.. } & \text {. } & \text {.. } & 44\end{array}$

$\begin{array}{llll}\text { Constituents of foods } & \text {. } & \text {.. } & 37\end{array}$

Cramming-machine $\quad$. $\quad$.. 41

$\begin{array}{lllll}\text { Cramp .. } & \text {. } & \text {.. } & \text {.. } & 44\end{array}$

Crop-bound $\quad$. $\quad$.

Crossbreds $\quad$. $\quad$.. $\quad \ldots{ }_{27}$

Diseases and remedies .. $\quad$.. 44

"Dont's" for poultry-keepers .. 50

$\begin{array}{llll}\text { Douglas mixture } & \text {.. } & \text {.. } & 37\end{array}$

Drink and food troughs .. $\quad \ldots 25,26$

Drinking-fountains $\quad$.. $\quad$.. $\quad 26$

Ducklings, brooding and feeding .. 46

$\begin{array}{lllll}\text { Duck-raising .. } & \text {.. } & \text {.. } & 46\end{array}$

Ducks, fattening $\quad$. $\quad$.. 41

$\begin{array}{lllll}\text { Dust-bath } & \text {. } & \text {. } & \text {.. } & 43\end{array}$

$\begin{array}{lllll}\text { Egg-eaters } & \ldots & \ldots & \ldots & 31\end{array}$

Egg-organs, disease of $\quad . \quad \quad \quad \ldots \quad 45$

Eruption on comb $\quad$.. $\quad$.. 45

Fattening ducks, geese, and turkeys 41

$\begin{array}{llll}\text { Fattening fowls.. } & \text {. } & \text {.. } & 40\end{array}$

$\begin{array}{llll}\text { Feeding chickens } & \text {. } & \text {.. } & 24\end{array}$

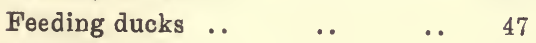

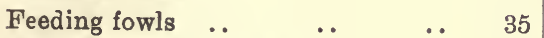

Feeding-trough, swing $\quad \ldots \quad \ldots \quad \ldots \quad 36$

Fertility of eggs .. $\quad$. $\quad$.. 33

Foods for poultry $\quad$.. $\quad$.. 35

$\begin{array}{lllll}\text { Fowlhouses } & \text {.. } & \text {.. } & \text {. } & 8-16\end{array}$

$\begin{array}{lllll}\text { Gapes .. } & \text {. } & \text {.. } & \text {.. } & 44\end{array}$
Geese, fattening $\quad$.. $\quad$.. 4 4I

Geese, raising .. $\quad$.. $\quad$.. 48

Hints to beginners -

$\begin{array}{lllll}\text { Capital } & \text {. } & \text {. } & \text {.. } & 5\end{array}$

Situation and soil $\quad$.. $\quad$.. $\quad 5$

Best breed to keep .. $\quad$.. 5

Houses and accommcdation $\quad .6 \quad 6$

$\begin{array}{lllll}\text { In breeding } \quad \ldots & \ldots & \ldots & 27\end{array}$

$\begin{array}{lllll}\text { Insect pests } & \ldots & \ldots & \ldots & 42\end{array}$

Instruction in poultry-keeping $\quad . .66$

$\begin{array}{lllll}\text { Leg-weakness } & \ldots & \ldots & \ldots & 45\end{array}$

$\begin{array}{lllll}\text { Limestone } & \text {. } & \text {. } & \text {.. } & 37\end{array}$

Male influence, duration of $\quad$.. 34

$\begin{array}{llll}\text { Medicated nest-egg } \quad . . & \text {.. } & 43\end{array}$

Mixing-trough for soft focds $\quad$.. $\quad 35$

$\begin{array}{lllll}\text { Movable coop } & \text {.. } & \text {.. } & \text {.. } & 17\end{array}$

$\begin{array}{llll}\text { Movable fowlhouse } & \text {.. } & \text {.. } & 16\end{array}$

Old stock and cookerels .. $\quad$.. $\quad 31$

Packing eggs for hatching $\quad$.. 34

Plans of brooders $\quad$. $\quad$.. $22-24$

Plans of fowlhouses $\quad$.. $\quad$.. $\quad 8-16$

$\begin{array}{llll}\text { Record, keeping } & \text {.. } & \text {. } & 32\end{array}$

$\begin{array}{lllll}\text { Roup .. } & \text {. } & \text {.. } & \text {.. } & 43\end{array}$

$\begin{array}{lllll}\text { Safety-nest } & \ldots & \ldots & \ldots & 31\end{array}$

$\begin{array}{lllll}\text { Scaly legs } & \ldots & \ldots & \ldots & 45\end{array}$

$\begin{array}{llll}\text { Scratching-shed } & \ldots & \ldots & 43\end{array}$

Sitting-bens, management of $\quad \ldots \quad 34$

$\begin{array}{lllll}\text { Sneezing } & \ldots & \ldots & \ldots & 45\end{array}$

Technical points of a fowl $\quad$.. 3

$\begin{array}{lllll}\text { Testing eggs } & \text {.. } & \text {.. } & \text {.. } & 19\end{array}$

Trap-nests-

Rose's $\quad$. $\quad$.

$\begin{array}{lllll}\text { Grant's } & \text {. } & \text {. } & \text {.. } & 30\end{array}$

$\begin{array}{llll}\text { Turkeys, fattening } & \text {. } & \text {. } & 41\end{array}$

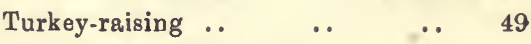

Why eggs fail to hatch .. $\quad$.. $\quad 33$ 



\section{NOTE.}

THis pamphlet is intended as a handy guide for farmers and others in practical methods of poultry-keeping. It is only in recent years that much attention has been given in New Zealand to poultry-rearing on a large scale, and it is not always recognised that a good deal of knowledge, as well as industry, is required to insure success. It is the desire of the writer to supply this knowledge and prevent beginners from falling into the mistakes which are often made and from spending money unnecessarily. Since the work of instruction was undertaken by the Government there has been a great improvement in the class of poultry kept by farmers, in the methods practised, and in the production of table-poultry and eggs. There is room for much further improvement, and in this direction the officers of the Poultry Division of the Department of Agriculture are always willing to assist with information and advice.

The results will depend, as in all business undertakings, upon the skill, industry, and business capacity of those engaged in it. With good management poultry-keeping will give steady cash returns at an early period after embarking in the enterprise, and no other class of stock will give so much profit on the capital invested as poultry will. Poultry-keeping should go hand-in-hand with dairying, also with fruitgrowing and bee-culture. In addition to their direct profit, poultry are valuable on the farm in enriching the soil or restoring impoverished soil to a fertile condition; in the orchard they search for and devour insects of all kinds, and not a grub will escape them.

Poultry-keeping is full of details: attend to these and success will follow.

January, 1908.

D. D. Hyde, Chief Poultry Expert 



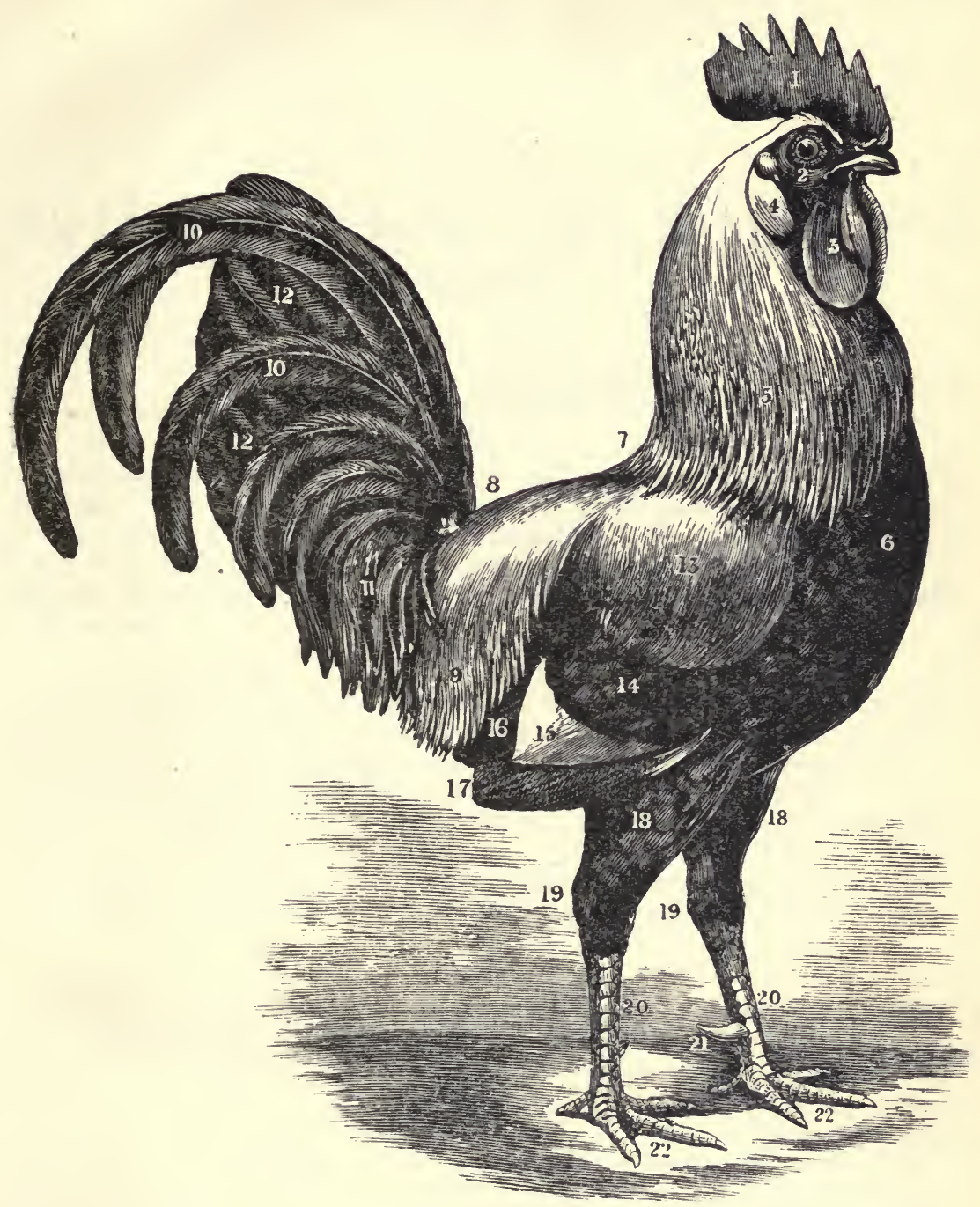

The Technical Points of a Fowl.

1. Comb.

2. Face.

3. Wattles.

4. Ear-lobe.

5. Hackle.

6. Breast.

7. Back.

8. Saddle.

9. Saddle-hackle.

10. Sickles.

11. Tail-coverts.

12. True tail-feathers.

13. Wing-bow.
14. Wing-coverts, forming the bar. 15. Secondaries, the lower ends forming the wing or lower butts.

16. Lower wing-butts.

17. Primaries. Hidden by secondaries when the wing is closed.

18. Thighs.

19. Hocks.

20. Legs or shanks.

21. Spur.

22. Toes or claws. 



\section{POULIRY ANI) EGGS FOR MARKEI' AND EXPORT.}

\section{HINTS TO BEGINNERS.}

Capital.

IN entering upon poultry-keeping as an industry sufficient capital is required to obtain land, build houses and yards, and buy stock or eggs; also to provide food for the birds and maintain the keeper until returns begin to be received. Begin in a small way and invest the capital by degrees, as it is required, and never resort to money on which interest must be paid.

\section{Situation and Soli.}

In choosing a site it must be borne in mind that a dry soil is required, a sandy loam being best. A north-east aspect, well-sheltered, is desirable. On a cold clay soil pullets will not lay in winter, and hens will be slow in moulting and only come on to lay when eggs are at a low price. It is not well to keep more than two hundred head to the acre, the number depending upon the richness of the soil. Poor land will probably give a better return if utilised for poultry-keeping than in any other way. Pure sand is undesirable, as it does not produce sufficient natural food.

\section{The Breed to KeEP.}

Which pay best, fowls for the table or eggs? is a frequent inquiry. As a rule either alone will not pay so well as both combined. To keep hens of the non-sitting breeds for eggs alone is to lose a profit that may be made on chickens. Some breeds will bring off a brood and lay nearly as many eggs in a year as those that do not sit. It is therefore advisable to pay chief attention to such breeds as Orpingtons, Wyandottes, Plymouth Rocks, and Houdans. If the soil is heavy and damp, Plymouth Rocks, Orpingtons, and Wyandottes will be the best breeds to keep; and on light dry soils Minorcas, Leghorns, and Houdans.

Do not attempt to keep half a dozen breeds of fowls, as each breed requires a separate run; and every additional subdivision adds considerably to the expense and labour.

Do not rush into the business and buy stock indiscriminately to start with. Be careful to select a good laying strain; show-points and feathers should be secondary considerations. Raise stock from a few well-chosen birds; buy these birds from the Department of Agriculture or from some other trustworthy breeder who only breeds from carefully selected, healthy, vigorous stock. Chickens hatched from inbred, sickly, or deformed stock will mean failure. It is a popular error to think that there is nothing to learn about poultry, excepting in the case of those kept for show purposes, 
and that all that need be done is to buy a few hens and a rooster, feed the birds year in and year out on wheat, and go round with a basket and gather up eggs.

Any one wishing to obtain the necessary knowledge to enable him to carry on poultry-farming successfully could not do better than spend some time as a student at one of the Departmental poultry-stations.

\section{INSTRUCTIONS IN POULTRY-KEEPING.}

The following particulars are published for the information of intending students:-

Conditions under which Students are ReCeived at the Government Poultry-stations.

The poultry-stations are at Ruakura, near Auckland; Moumahaki, near Waverley; Burnham, near Christchurch; and Milton, near Dunedin.

A limited number of students are received and instructed under the following conditions :-

(1.) They must pay their own travelling-expenses.

(2.) At Moumahaki board and sleeping-accommodation are available at the Government Experimental Farm, at about 12s. per week; students must, however, supply their own blankets. At Ruakura, Burnham, and Milton no Government accommodation is available, but board and lodging can be obtained privately within a convenient distance.

(3.) Students are expected to stay at least six weeks at the poultrystation.

(4.) They receive no wages, but must do such work in connection with poultry as the manager of the station may require of them.

\section{Practical Advice.}

Poultry-keepers requiring any advice on poultry matters should arrange for a visit from one of the experts, by making application to "The Chief Poultry Expert, Department of Agriculture, Customhouse, Wellington."'

Intending poultry-keepers should avail themselves of the experts' services when selecting stock and arranging the situations, plans, equipment, \&c., for their poultry-houses and yards, and thus avoid many of the mistakes frequently made by beginners.

Incubators, brooders, and the other machines used in poultry-keeping are now familiar to most of those interested in the industry, and the illustrations of these appliances which appeared in the earlier editions of this pamphlet are therefore omitted. The respective agents will supply illustrated catalogues and full particulars, free, on application.

\section{HOUSES AND ACCOMMODATION.}

To be successful in poultry-keeping it is absolutely necessary to have suitable premises for the fowls to live in. "They should not be permitted to roost in trees, as when they become soaked by rain part of their animal heat is used in evaporating the water, and egg-production is checked. If only to economize food, shelter should be given from cold winds and rains. 
It is not necessary that the buildings should be elaborate in construction, but they should be just large enough to accommodate the number of birds you wish to put in them, allowing 15 to 20 cubic feet of air-space for each bird. It is a fatal mistake to have fowls overcrowded; therefore scatter them as much as possible into small flocks.

As a general principle, a house $7 \mathrm{ft}$. square and the same in height will accommodate twenty-five fowls.

Place in the fowlhouse a large window facing the north-east, in order to admit as much of the sun's rays into the buildings as possible. This is a provision that is too frequently overlooked. The front of the breeding-pens should face the rising sun.

If galvanised iron is used for roofing the building it should have boarding under it, owing to the iron being a rapid conductor of heat and cold.

The building must be well ventilated, but there must be no draught. The importance of this is very generally ignored, so that it is quite the exception to find poultry-houses constructed with any attempt at ventilation. If the house is visited two or three hours after the birds have gone to roost it can be readily ascertained whether it is sufficiently ventilated or not; the atmosphere should strike rather warmer than that of the outer air, but there should be an absence of closeness or smell. To enable the proper medium to be arrived at, a small opening about 12 in. by 6 in. should be made at the upper part of the house, and covered with perforated zinc or small-mesh wire netting, and arranged so that it may be entirely or partially closed; a board to slide in grooves, similar to those generally made to cover the hole by which the fowls enter the house, will be as suitable as anything.

A boarded, concrete, or asphalt floor should not be used; earth only is required, and should be built up inside the fowlhouse 6 in. higher than the surrounding ground, in order that it may be kept dry.

The perches should not be placed high,-or so that the heads of the birds can come on a level with the ventilator. They need not be more than 12 in. from the floor, and they should be all on a level. The step-ladder style that is often adopted is a mistake; the fowls will invariably try to get on the top perch, which is generally near the roof, and the air they breathe becomes vitiated, and disease follows. Do not nail the perches, but have them fitting into a slot, so that they can be easily removed, and the ends dipped into kerosene occasionally. A perch should be 2 in. wide by $3 \mathrm{in}$. deep, made of sound timber (if there are any cracks they will harbour vermin), with just the rough edge taken off.

The buildings shown in this pamphlet are those in use at the Government poultry-stations, and are suitable in every way as breeding-pens. The main flocks are put out about the farm in movable houses, $7 \mathrm{ft}$. by $5 \mathrm{ft}$., an arrangement I strongly recommend to farmers, as the fowls by this system require very little feeding, so long as the houses are moved on to fresh ground once a week.

The movable house referrêd to is illustrated on page 16 . 


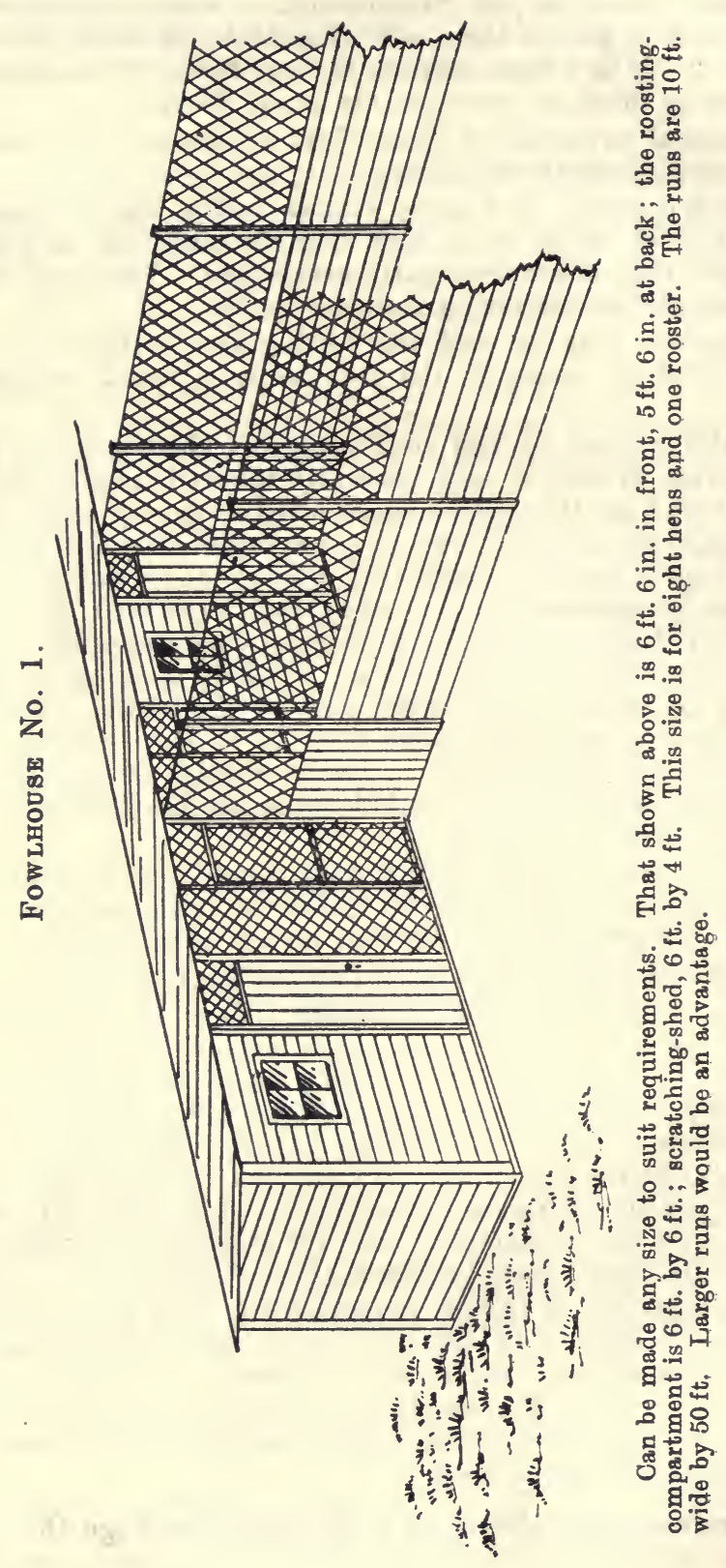




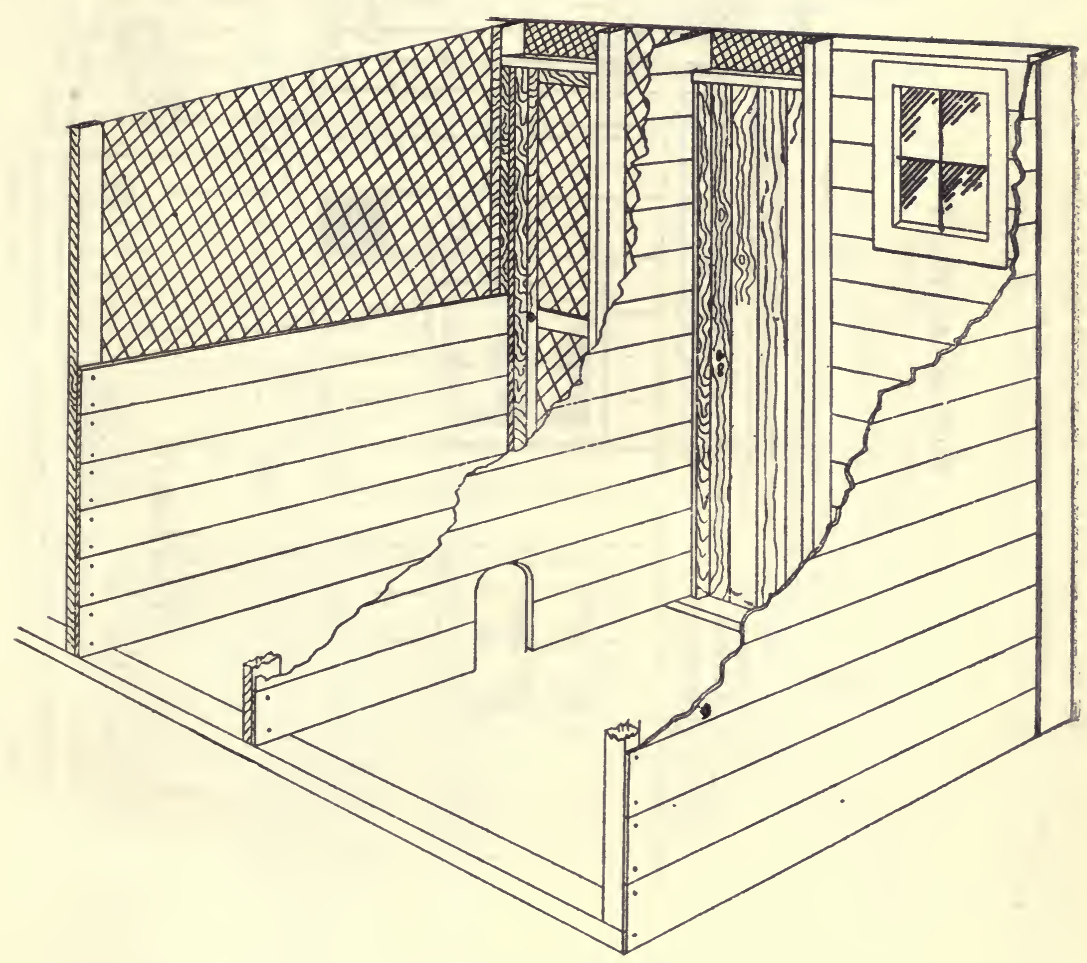

Interior of No 1. 

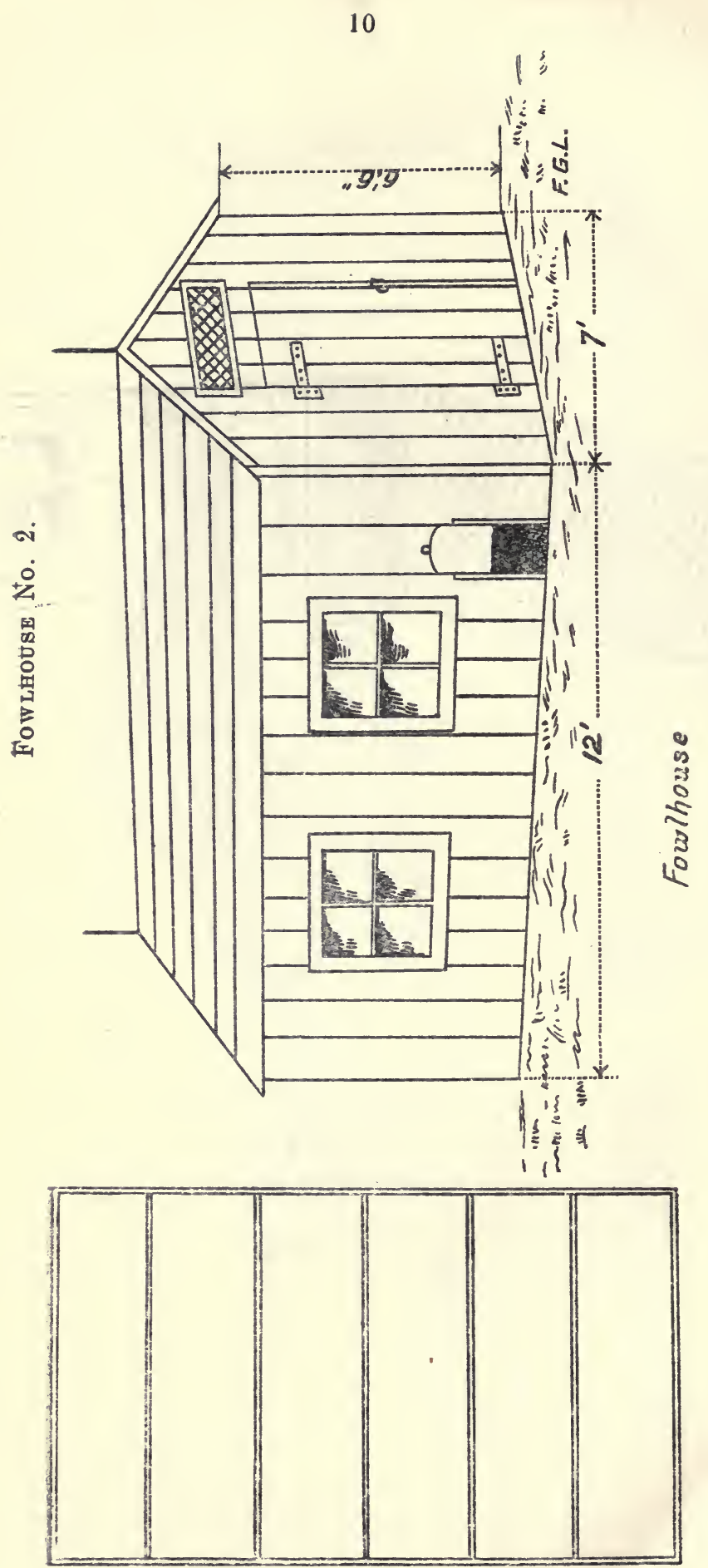

Ferches 


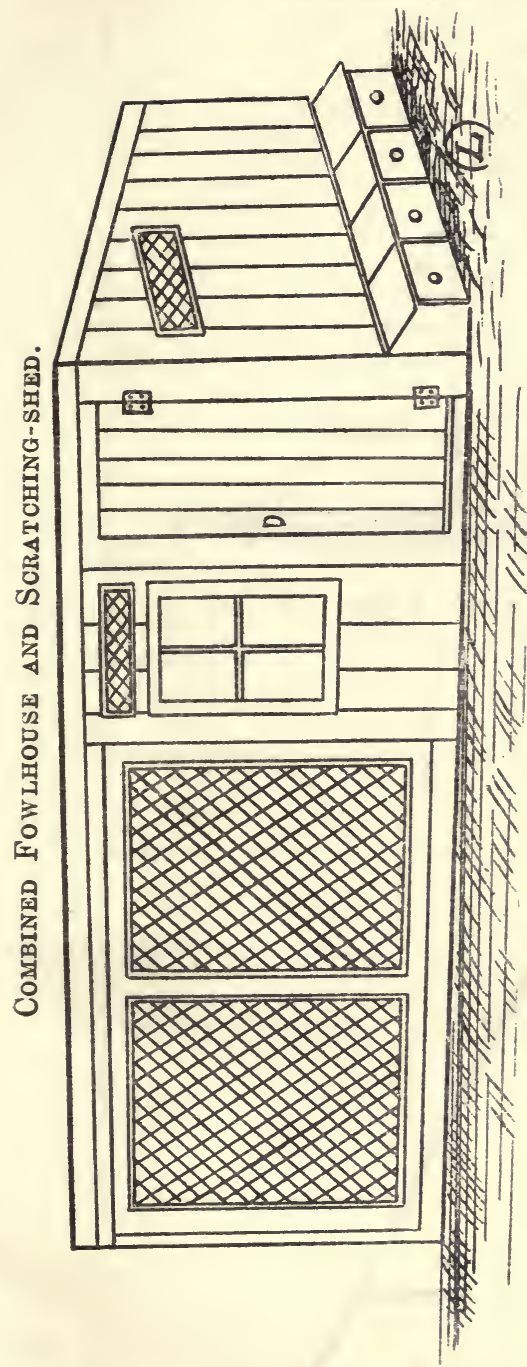

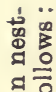

3눈

요

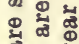

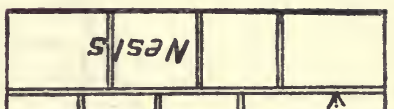

-

드응 몽

웡 을

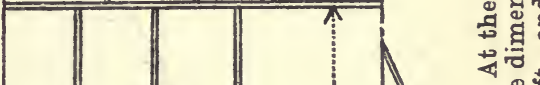

प्रें

है

品 모운 느을 을 $\frac{9}{1}$ 응 빼웜 릉 क्ष 요요

तु है 용 فำ . จุ 온옹수 造运 额

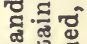
Фํㅡㅇ 号 0 오요 B 에 현 훈

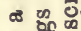
of 80. 눙 芯 숭ㅎㅇ 过 ० 윤 ๙ జ 원 용 这费 궁응 


\section{A Cheaply Constructed Fow luouse}

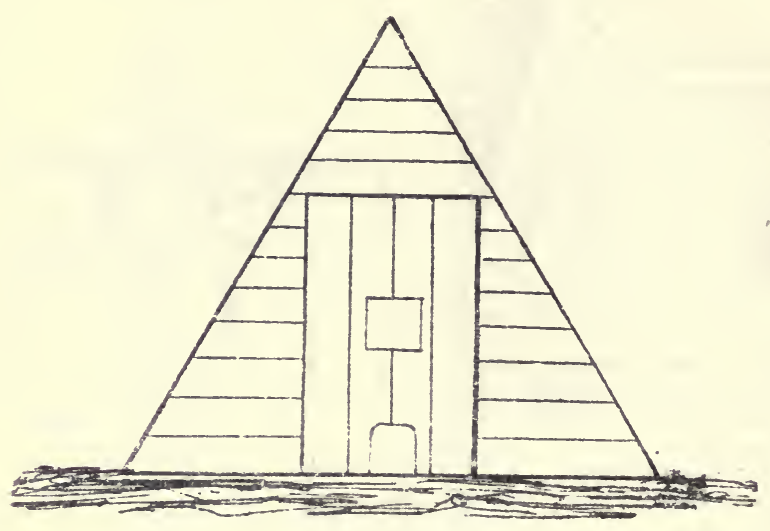

- Front elevation, $7 \mathrm{ft}$. ; width of face, $7 \mathrm{ft}$.

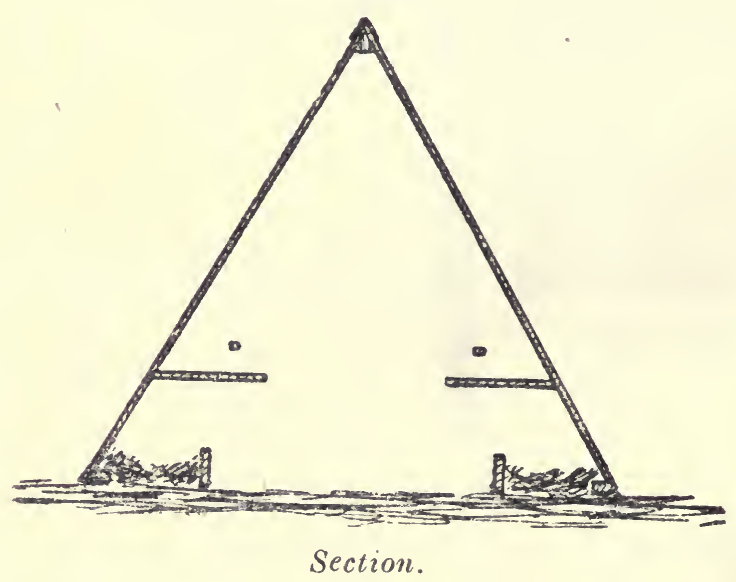




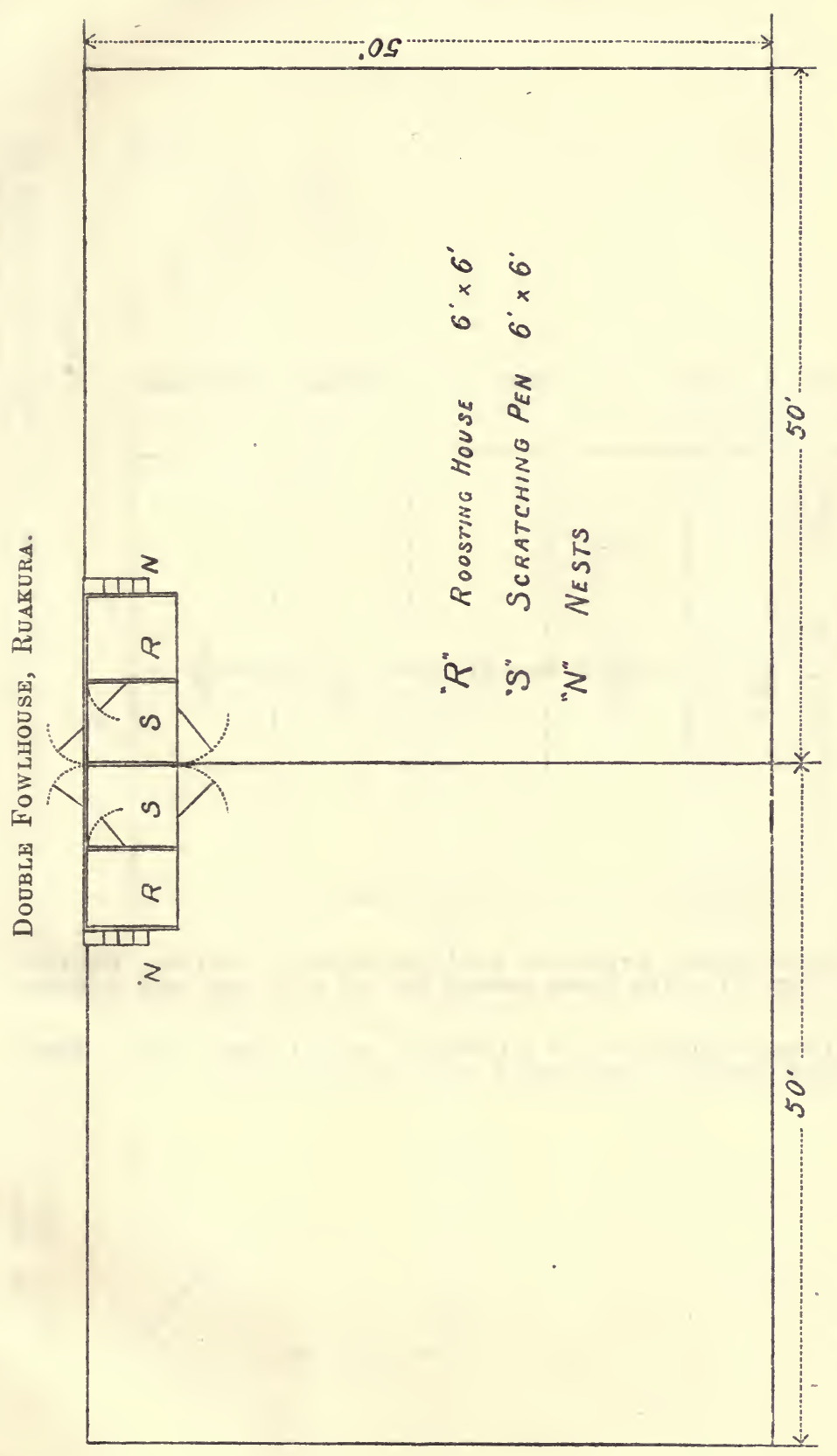

눙 오.․․

도웡을

ธิ ฉ

웡

ํㅡㄹ 돌

모을

ดี

递

4

올을

앵

w :

อง

옳

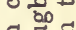

สี 릴퓨

대를

品娄

ㄷํㅇ

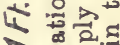

" का ?口.

-10 क क

(1)

م

용

ง

बै

ผื

o.

\$ิ

क

吕

要

우ㅇㅝㅠ

$3 \%$

วิ

등 융

:

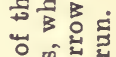

跑

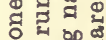

ㄴㅇㅇㅢ

वृ से क

‥ 요

'宊离总

ठิ응

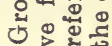

正

范。 
Plan of Double Fowlhouse with Alternative Runs.

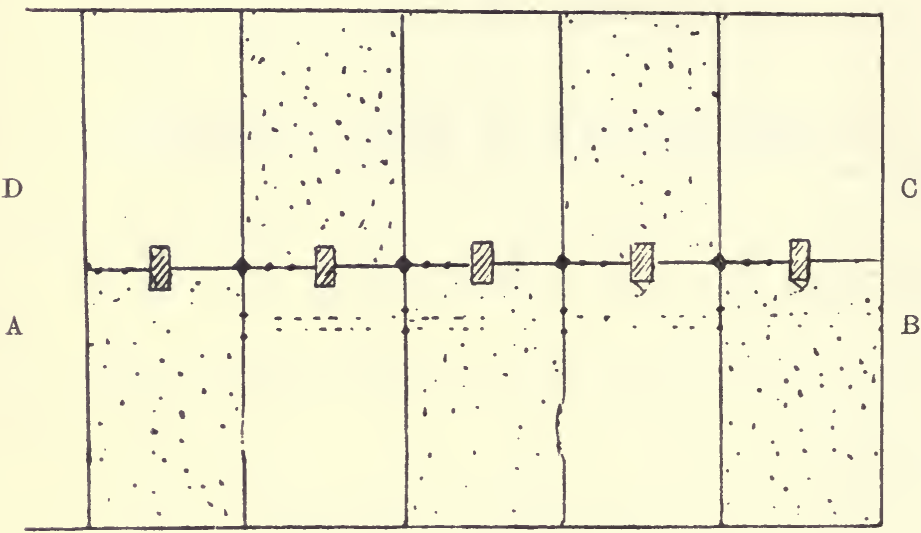

This illustration shows a system of double houses and double runs. The runs measure $50 \mathrm{ft}$. by $30 \mathrm{ft}$. The houses measure $6 \mathrm{ft}$. by $12 \mathrm{ft}$., and have a central division.

NotE.-Through inadvertence the gateways are omitted from the plan. These should be in line through the runs from $A$ to $B$ and from $C$ to $D$. 

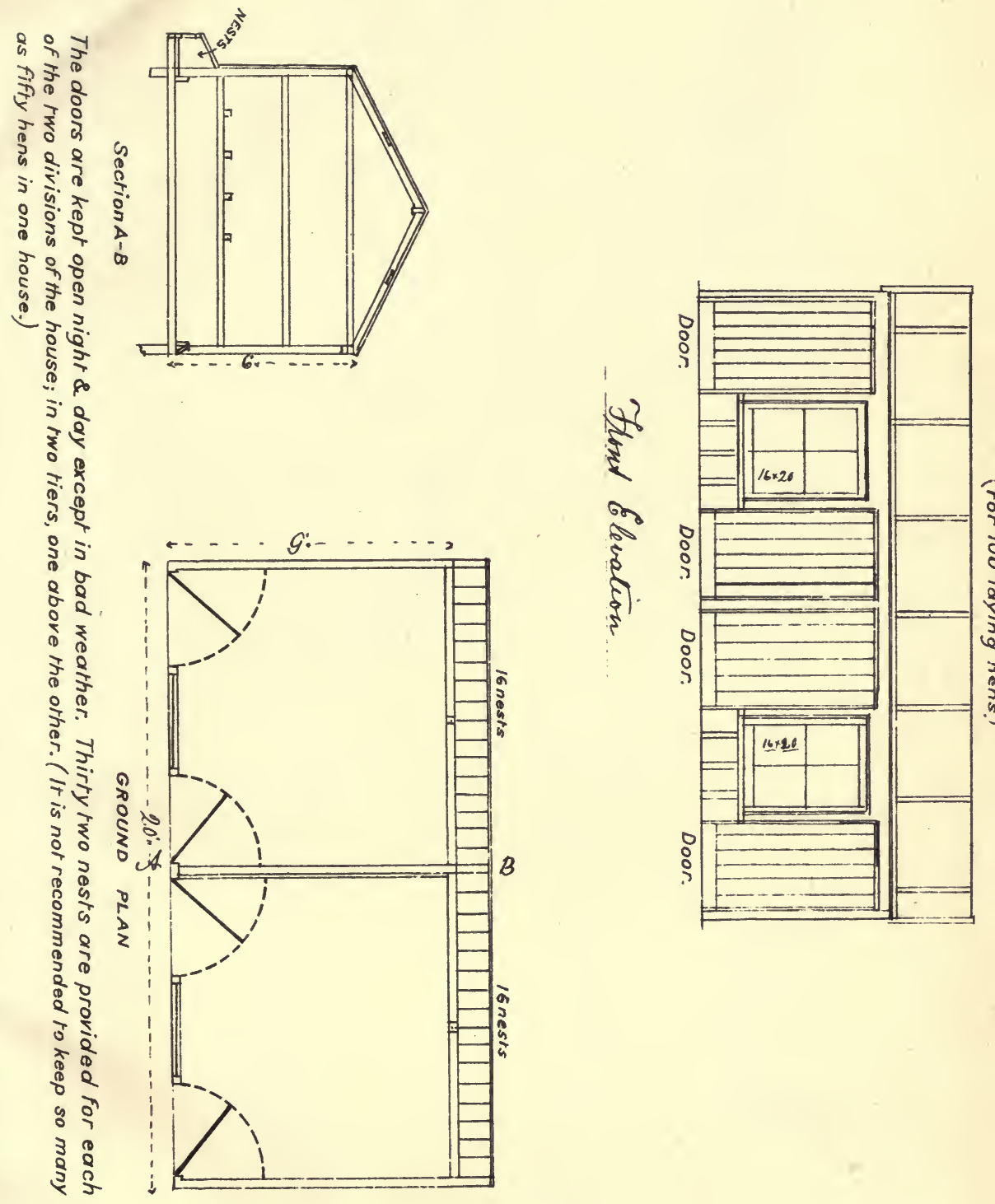


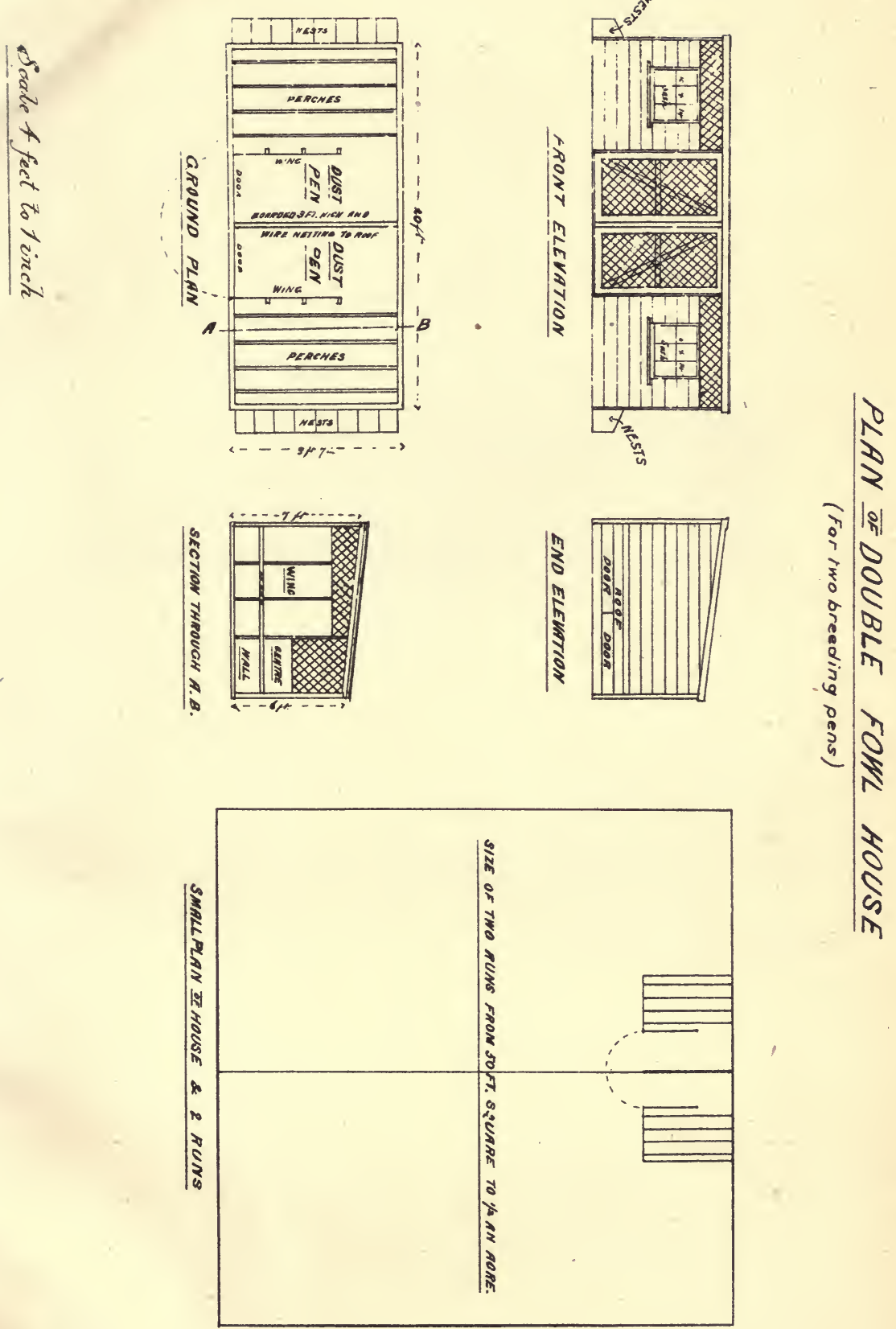

Double Fowlhouse.

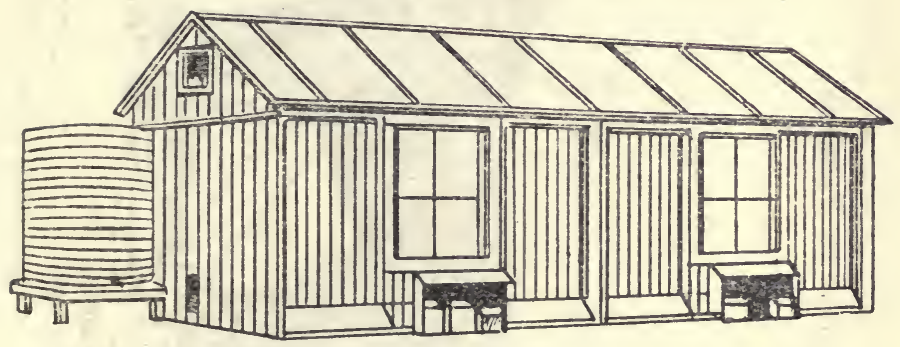

Specification of Double Fowlhouse (see Plan).

Foundations.-Concrete or piles.

Framing.--Plates, studs, rafters, and rossts, 3 in. by 2 in. ; 4 battens for iron and angle-stops, 3 in. by $1 \frac{1}{2}$ in.

Spacing.-Piles to be placed not more than $3 \mathrm{ft}$. 6 in. centres; studs, not more than $2 \mathrm{ft}$. centres; rafters, $2 \mathrm{ft}$. 6 in. centres.

Weatherb ards. - All outside walls, and wing-wall separating dust-bath from perches, covered with 8 in. by 1 in. rusticated weatherboards. Centre partition of building, rough-boarded $3 \mathrm{ft}$., remainder wire netting to roof.

Doors.-Door-frames 4 in. by 1 in., braced, and covered with wire netting.

Wire Netting. $-1 \mathrm{ft} .6 \mathrm{in}$. netting to be fixed on front walls and top of wing-wall where shown.

Roof.-Half-inch sarking on battens, $10 \mathrm{ft}$. iron.

Nests. - To be constructed of 1 in. boards, as shown.

Spouting.-Back wall, $4 \frac{1}{2}$ in. ogee spouting and downpipe.

Painting.-Two or three coats of good oil paint. 


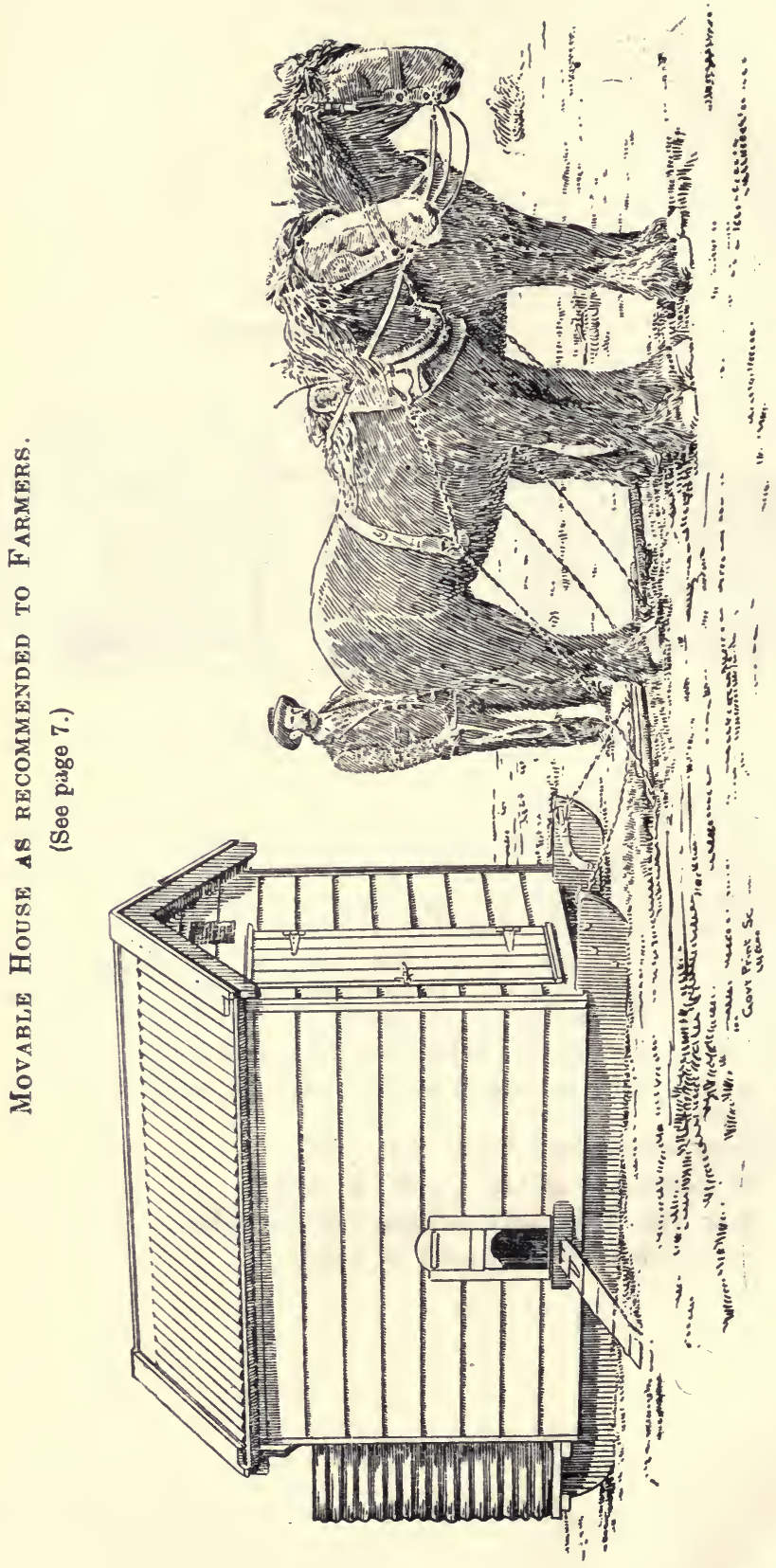




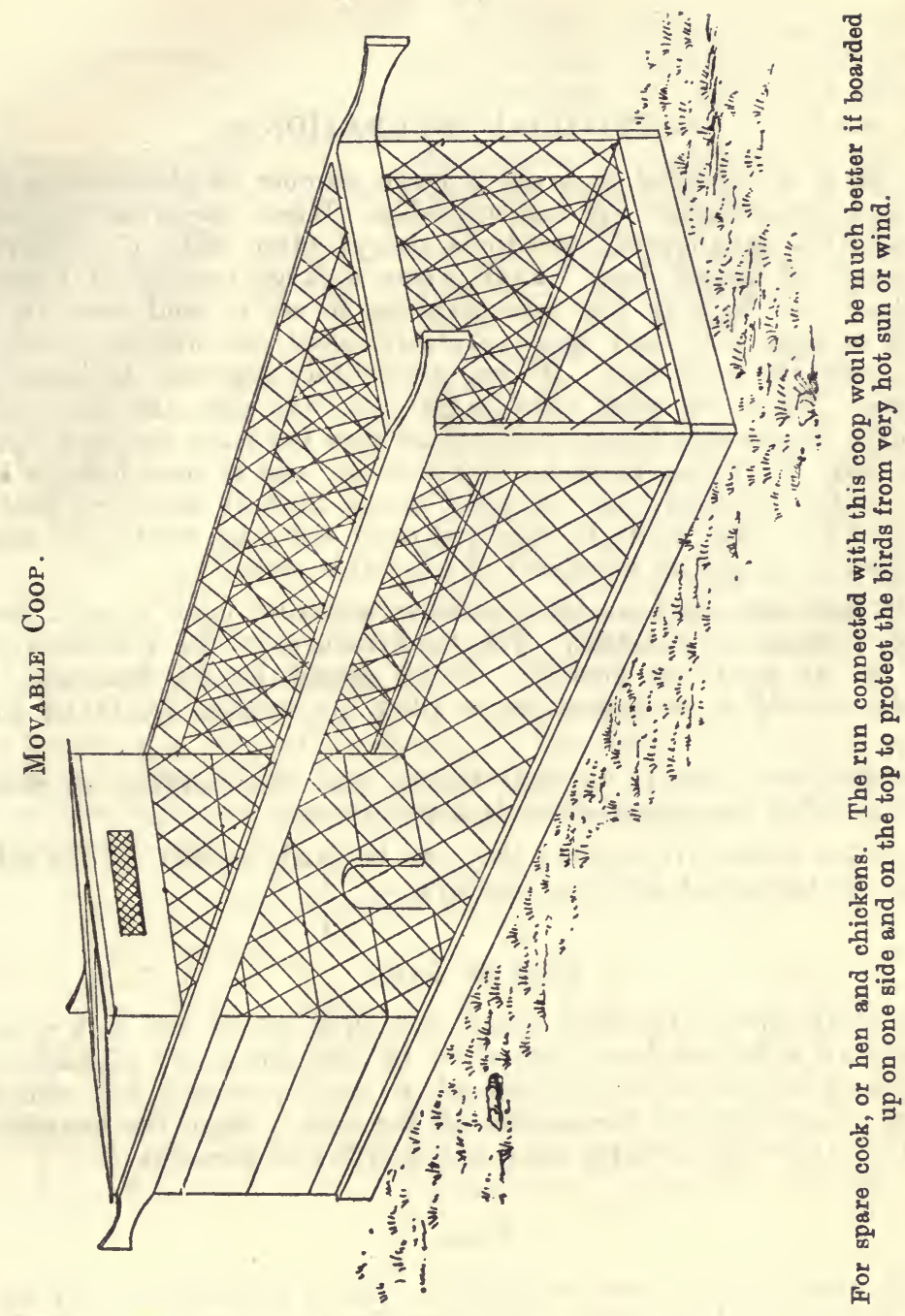

\section{DUCK-HOUSES.}

The cheapest style of house is one with a slanting roof. It should be $6 \mathrm{ft}$. high in front and $4 \mathrm{ft}$. $6 \mathrm{in}$. high at the back. There should be one window with a sash of six lights, 9 in. by 12 in., for 10 running feet of the building. Provide plenty of ventilation. The ventilators should be near the roof, and so arranged that there will be no draught. Seven square feet of floor-space should be allowed for each bird. Wire netting $2 \frac{1}{2} \mathrm{ft}$. in height will be ample to divide the flock. The interior of the building must be kept clean, and dry straw used for bedding. The birds will make their own nests in the straw, so there is no need to provide nest-boxes. In the northern parts of New Zealand it is unnecessary to provide houses for ducks-the climate is so mild that the ducks will not make use of a building. 


\section{ARTIFICIAL INCUBATION.}

Where it is intended to breed a large number of chickens an incubator and foster-mother are indispensable. When the ordinary method of incubation is adopted, vexatious delays often take place through the scarcity of broody hens. Even where a large number of fowls are kept there will be very few hens wanting to sit in cold weather, and sittings of eggs that have been carefully saved are wasted because no broody hens are to be had. By using machines eggs can be hatched at any time. There are other advantages-viz., the eggs are not crushed, as so often occurs with hens; the machine does not leave the eggs, neither does it cover the young chickens with vermin, and it costs less for kerosene to hatch out, say, one hundred chicks than it would to feed the number of hens that would be required to do the same work. Of course, it is necessary to get an incubator of a reliable make.

It is important to have the incubator standing upon a solid floorthe less vibration the better. The temperature in the incubator-room should be as equal as possible; there should be no draught. The incubator should be so placed as to allow air to pass freely all round it.

The incubator should be well tested, and the working thoroughly mastered, before the eggs are put into the drawer.

When the chicks are hatched they can be easily reared, in the coldest weather, by the aid of artificial mothers.

\section{Care of Lamp.}

The lamp should be filled every day with oil of the best quality. Always have sufficient flame turned on to keep the valve slightly open. Do not turn the flame up high enough to smoke, or soot will collect in the flue. Carefully cut the corners off the wick. Keep the burner free from dirt, and wipe from the lamp any overflow of kerosene.

\section{EGGs.}

Eggs should be as fresh as possible; but a good hatch may be obtained from eggs three weeks old, especially if the weather is cool and the eggs are turned over every twenty-four hours.

Eggs for setting should be collected regularly and placed in a room where the temperature is never below $40^{\circ}$ or higher than $65^{\circ}$.

Place the eggs in the drawer so that the large end has the highest position.

\section{Temperature.}

The proper temperature for either hen or duck eggs is $103^{\circ}$. There need be no alarm if the temperature should run up to $107^{\circ}$ for an hour or two; but if left longer the germ will be destroyed. 


\section{- Testing Egas.}

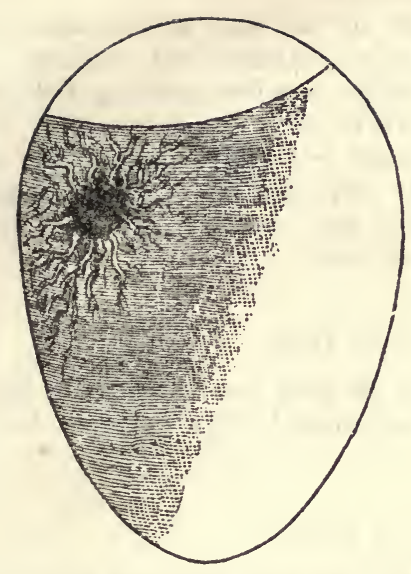

Fertile Egg.

This is a very necessary proceeding, in order to remove any infertile or dead eggs. As there is a difference of about $3^{\circ}$ between a dead and a live egg, there is a danger of the thermometer bulb resting on a bad one, and the live ones becoming overheated. The best time to make the first test is on the fifth or sixth night. Hold the egg between the forefinger and thumb, or in a tester that is usually supplied with incubators; look through the egg at a strong light. If the egg is fertile it will appear like that shown in the margin, and slightly red in colour; if addled, a black spot will be visible; if infertile, it will be quite clear. The latter may be used for culinary purposes, or boiled for chickens already hatched. A second testing

about the twelfth day is advisable.

An ordinary small lamp or a candle may be utilised as an eggtester by fixing a piece of cardboard, in the centre of which an opening the size and shape of an egg has been cut, in front of the flame. The rays of the light are thus focussed through the egg. Reliable results are obtained in this way.

\section{DeVELOPMENT OF THE AIR-CELL.}

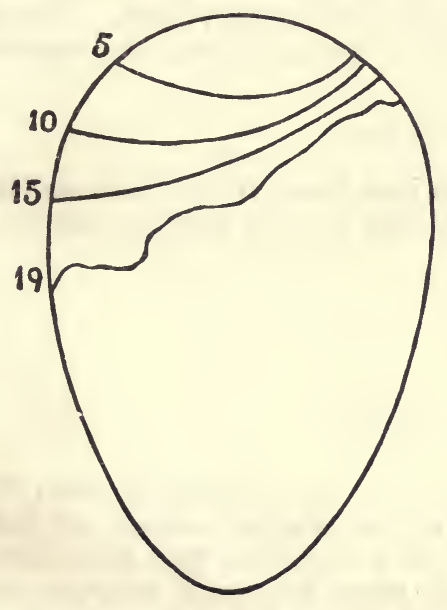

HEN EGG.

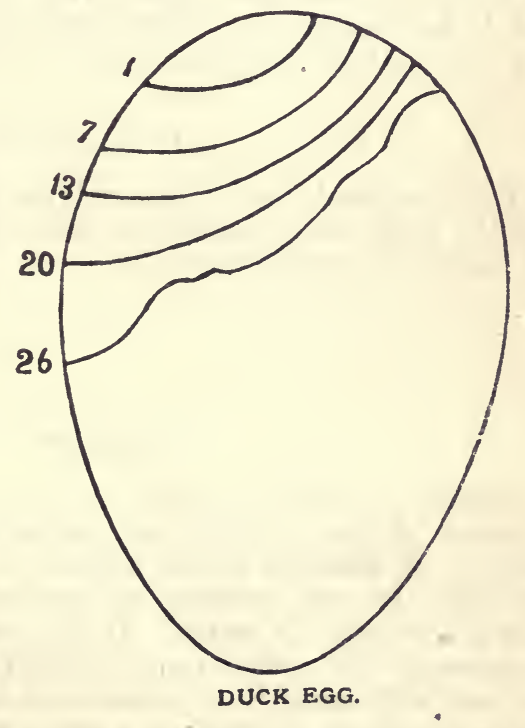

A capital plan is also to note the development of the air-cell; it becomes larger as the chick develops. The diagrams show the development that should take place at the respective number of days. 


\section{Ventilation and Moisture.}

The moisture or air-saturation is affected by the size of the opening of the ventilators. A wide opening of the ventilators will reduce, a small opening will increase, the moisture. With a wide opening the air moves through the machine rapidly and carries the moisture out. In starting the machine open the ventilators, and gradually close them as necessity demands. Thin, porous shells dry rapidly, while thick shells are slower, and if eggs from different varieties are placed in the machine at the same time an average will have to be struck.

\section{Start all the Eggs at One Time.}

When starting a machine put all the eggs in that you intend for that particular hatch; it is a mistake to put additional eggs in from time to time.

\section{Turning and Cooling the Eggs.}

Turn the eggs night and morning after they have been in the machine forty-eight hours. It is well to mark the eggs on one side thus, so that the marked side is visible on one occasion and out of sight next. They should not be turned exactly half way; the position should be varied. Allow them to cool about ten minutes at first, and gradually increase the time till the third week; they may then remain out of the machine from thirty to sixty minutes, according to the weather. It is advisable to change the position of the eggs occasionally; those that are on the outside of the tray one day should be placed in the centre the next. Cease turning the eggs as soon as they commence to pip (i.e., as soon as the chickens crack the shells), and on no account allow the incubatordoor to be opened after that till the hatch is completely over. This is a very important point, and curiosity should not cause it to be forgotten.

\section{Crippled Chickens.}

This trouble is caused through the chicks being in the shell too long, and the heat being allowed to run too low or too high at some time during the incubating period.

\section{BROODING CHICKS.}

Success in raising chicks depends largely on preventing them from becoming chilled. Chills and exposure are common causes of boweltrouble. If chickens huddle together it is a sure sign that more heat is required. In cold weather chicks need more heat and covering than when the weather is warm. If the food is given in the brooder (which is necessary with quite young chicks) remove it as soon as possible, as the heat will cause it to steam and become sour. Crowding chicks in poorly ventilated brooders is a grave mistake; crowding under the most favourable conditions should be avoided, or the mortality will be great. Although $3 \mathrm{ft}$. square is generally claimed as sufficient for one hundred young chickens, double that space is desirable for the number stated. 



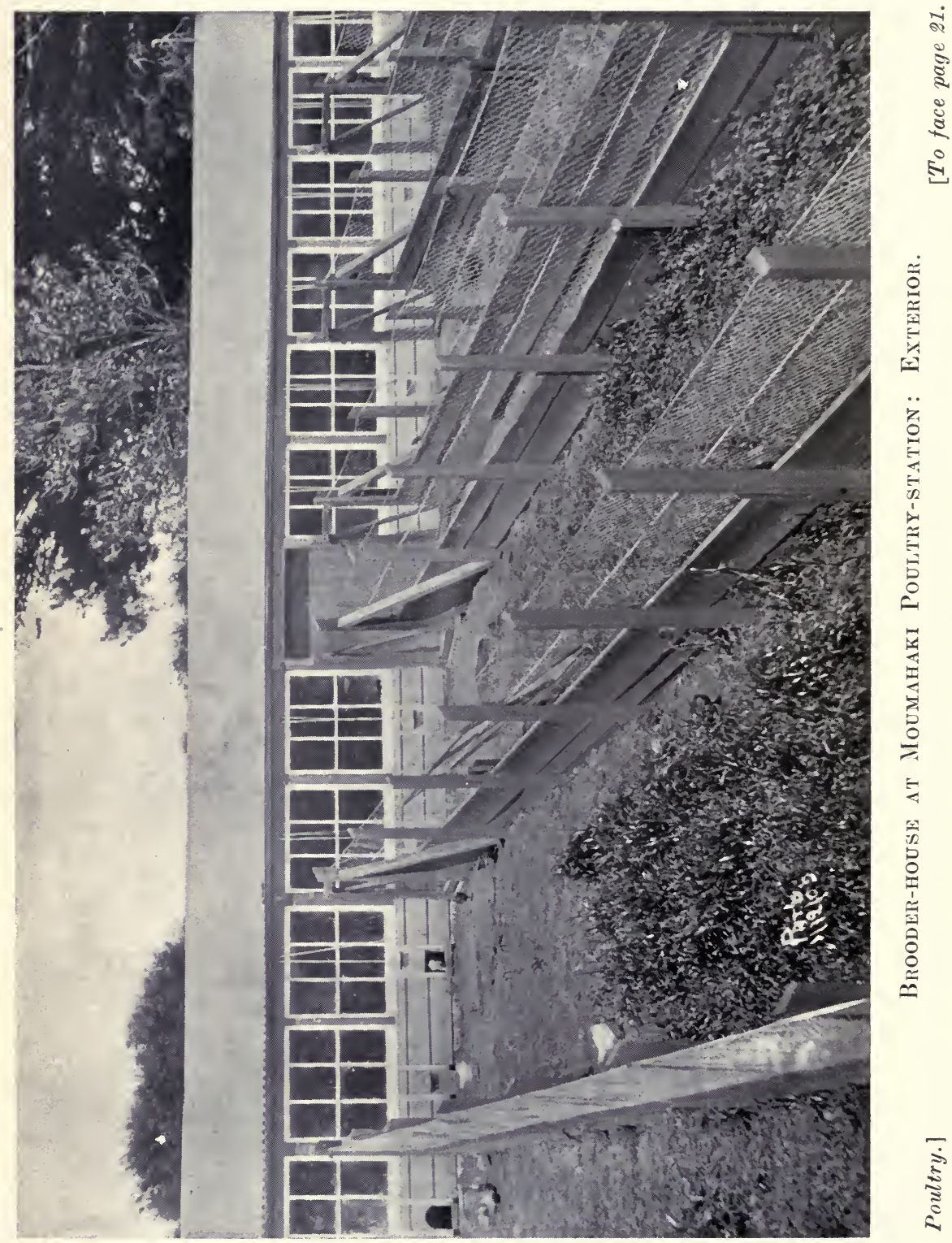





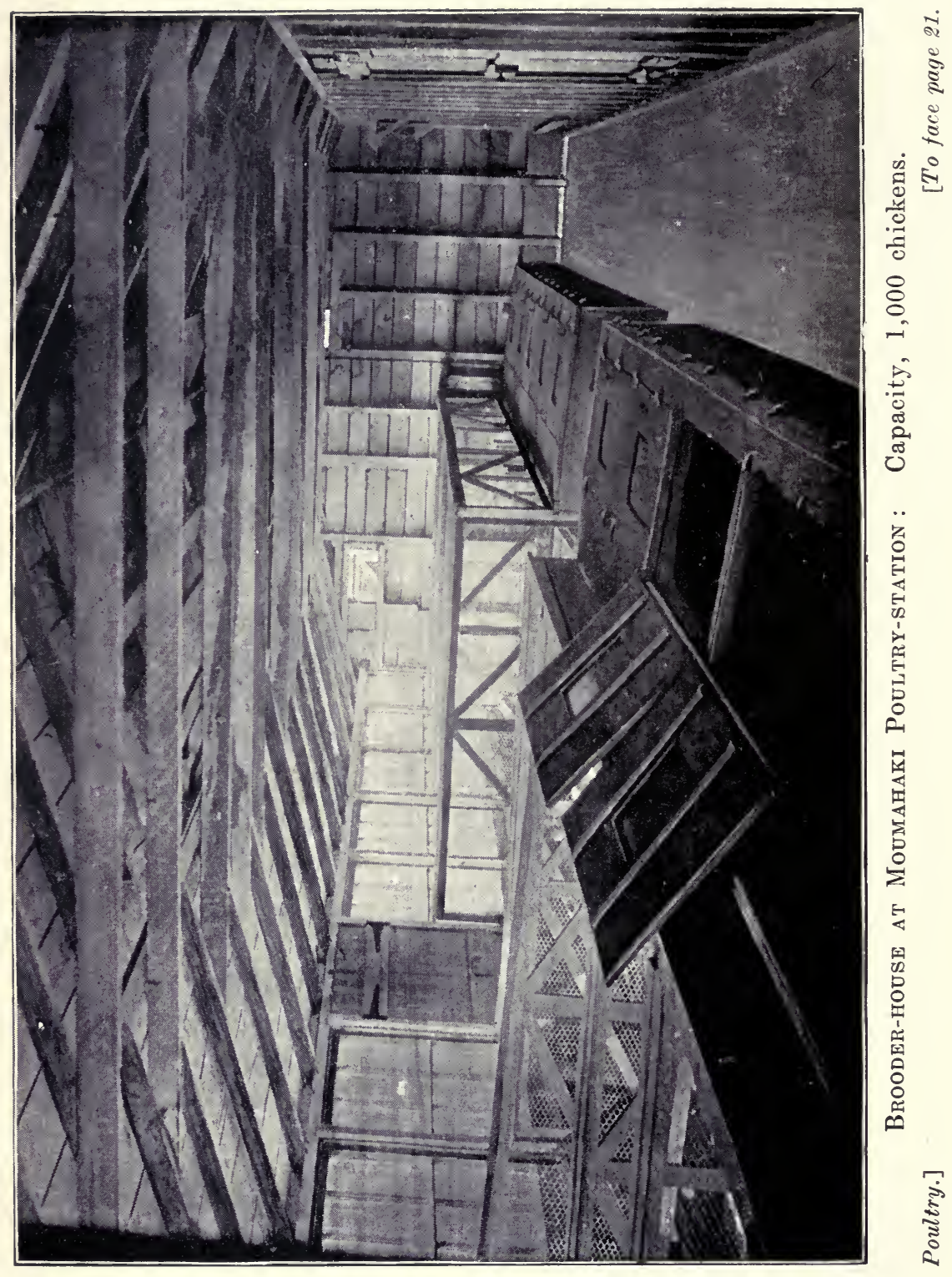


The heat in the brooder for the first week should be $98^{\circ}$, and be gradually reduced after the chicks are a fortnight old, according to the weather and the age of the chicks. If a cold night is expected give additional heat. If the chicks are too warm they will move away from the main volume of heat.

When the chicks are five days old give them strips of tough meat in order to make them run in and out of the brooder for exercise. The chicks must have exercise and fresh air; do not coddle them or they will become stunted in growth.

Do not have chicks of various ages run together, as the big ones will rob the younger birds of their share of food.

Do not let the chicks get wet; the drinking-vessel should be so arranged that the birds can reach the water with their beaks only. Clean water should be kept constantly before them.

Do not allow the chicks to get a chill when removing them from the incubator to the brooder; use a piece of flannel or blanket to cover them.

It is most important that young chicks should for the first three or four days spend all their time in the brooder. Then begin to let them outside, penning them near the brooder to prevent them straying away and getting chilled. Chicks should be brooded for about six weeks, according to the weather; a little experience will soon determine this.

The brooder must be kept clean, and fine sand or dry earth $\frac{1}{4}$ in. to $\frac{1}{2}$ in. in depth covering the floor. Pine-needles are also very suitable for this purpose. 
Brooders at Moomahaki and Burnham Poultry-stations. No. 1 .

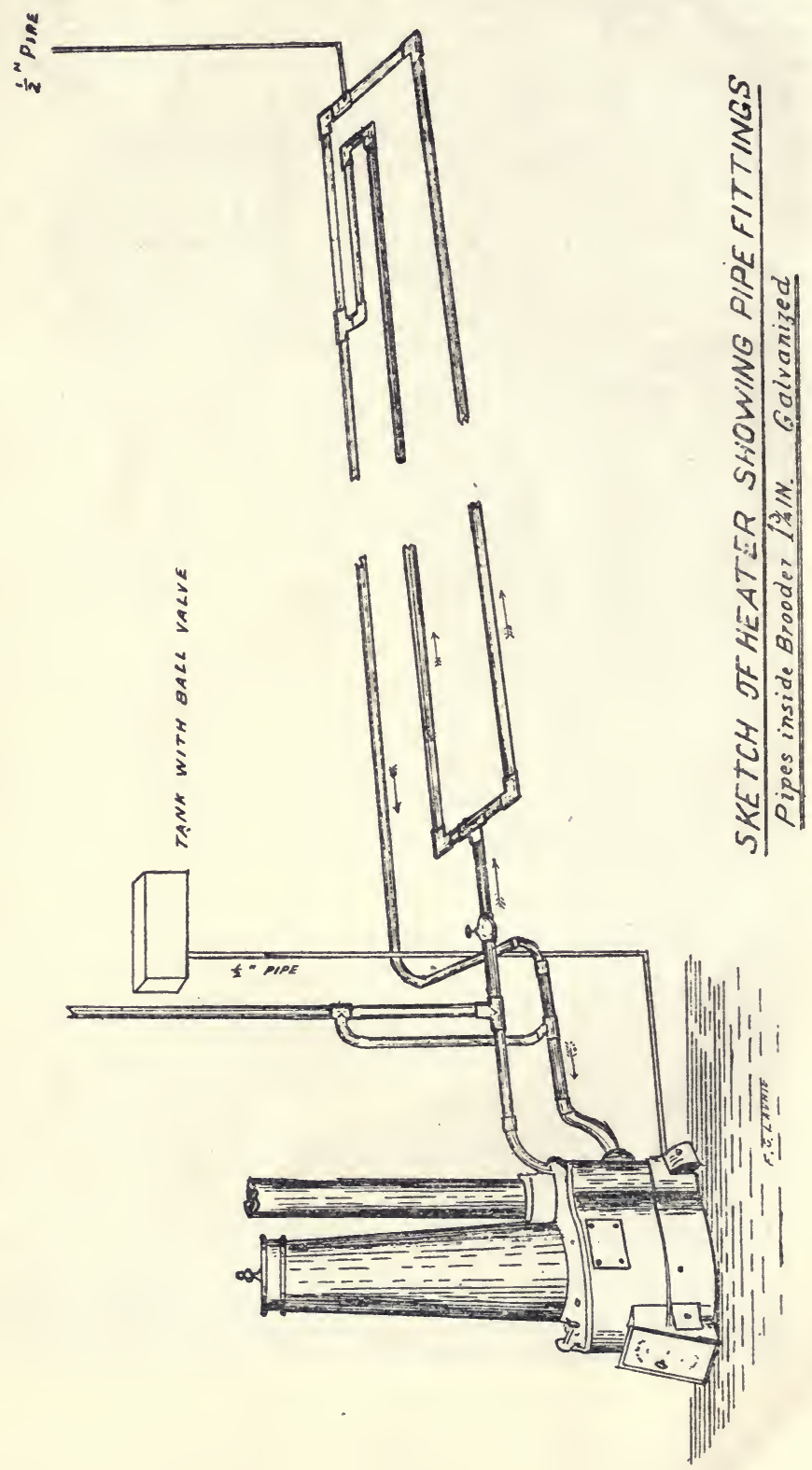


No. 3.

No. 2.
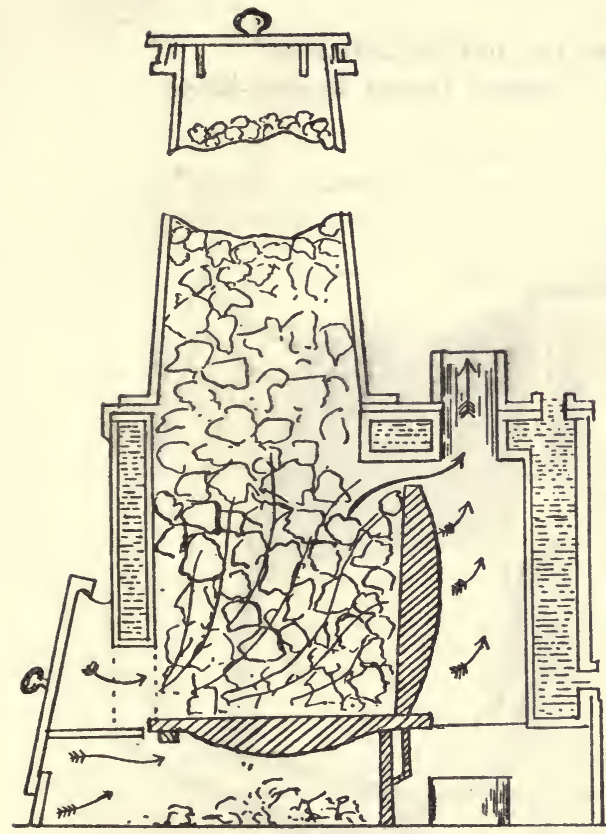

SECTION NOJ BOILER

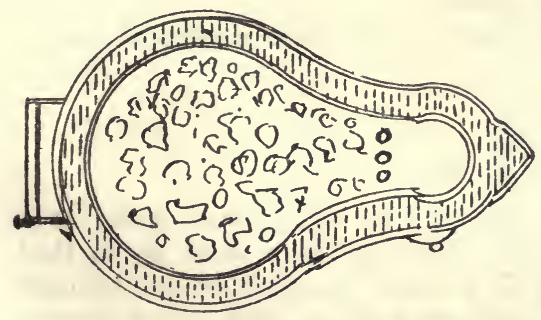

HORIZONTAL SEGTION

These illustrations (Nos. 1, 2, and 3) give details of the "twelve-hours stove" and the pipe arrangements for the brooders as used at the Government poultry-stations at Moumahaki and Burnham. For those, who $\mathrm{w}$ ish to raise a large number of chickens this system can be recommended, first, on account of the small cost at which the stove can be run, and, secondly, because of the great saving of labour. 
Specification of Brooder (see Plan).

Timber.-Brooder should be covered with $\frac{7}{\mathrm{~g}}$ in. or $1 \mathrm{in}$. boards, thoroughly seasoned.

Lining.-Under-side of top boarding between wire netting and glass to be lined with galvanised iron, to confine the heat.

Felt.-To be fixed with strips of wood.

Bottoms.-With board run hinged on front so as to move up or down, and fixed with hooks.

Glass Lids.-In four sections, with two squares of glass in each, hinged to cover or top boards.

Piping.-Of 1 in. gas-piping.

Length.-The length of brooder may be varied to suit circumstances.

Lamp.-Details of lamp should be similar to Cypher's Duplex Brooder-lamps.

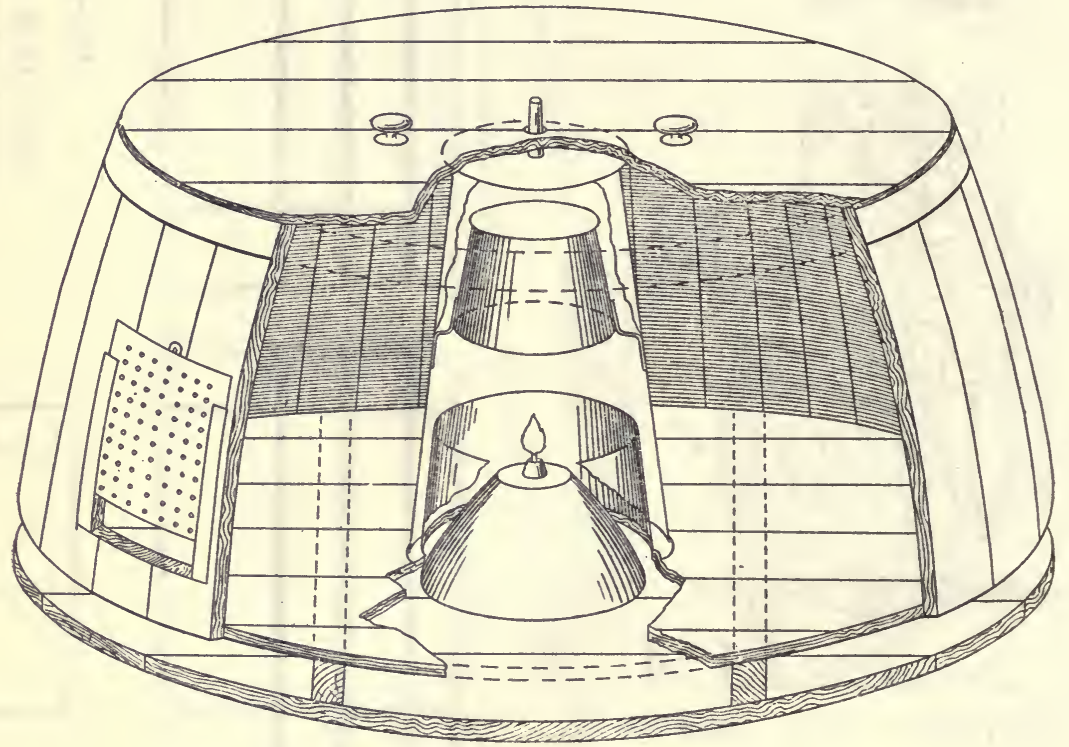

Calway Brooder.

A cheap and useful brooder for thirty-five chicks, made from portion of cask.

\section{FEEDING CHICKENS.}

Chickens should not be fed for forty-eight to sixty hours after they are hatched, as nature has supplied them with all they need up to that time. They should then be supplied with a small quantity of hard-boiled egg, shell included, put through a mincing-machine, also bread-crumbs and oatmeal, mixed with boiled milk (if you have this to spare) and made just moist enough to break easily. Avoid above everything giving chickens sticky or sloppy food, and do not give more than they will eat up clean at a time. For the first week they should be fed during the day every two hours, and for the second week every three hours.

The chick should, from the day it leaves the shell until full growth is reached, be made to gain weight. There must be no check, or it will cost far more in food to bring the bird to maturity. 

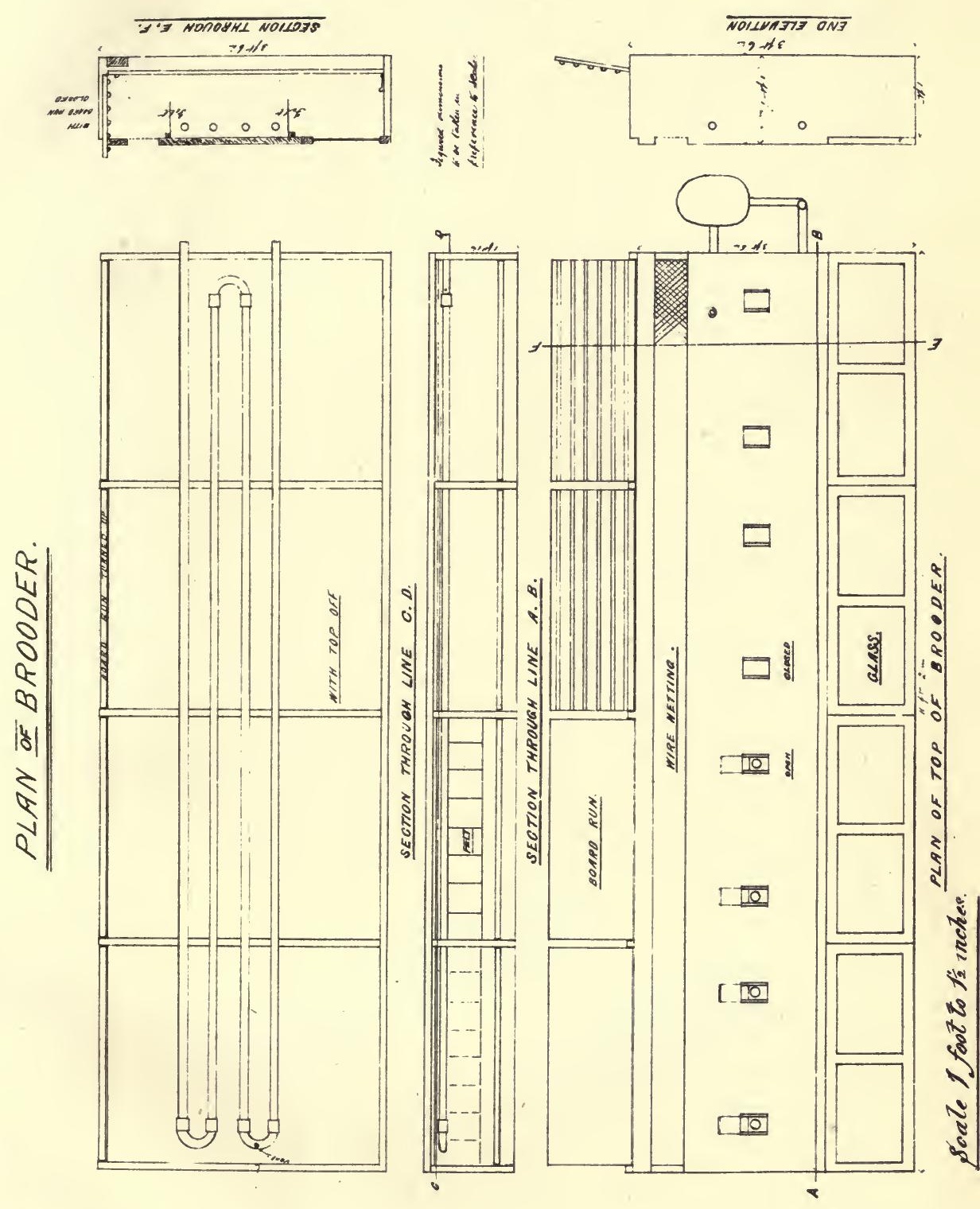

In feeding chicks use a trough, as illustrated herein, or a clean board; if the latter is used sprinkle the food upon it, adding more if necessary. When the chicks have had sufficient, remove the trough or board. These should be kept thoroughly clean. Discontinue giving hard-boiled eggs after the second or third day. Then give coarse oatmeal, following with crushed wheat, barleymeal, maizemeal, \&c., alternately. It is advisable to sift barleymeal and rolled oats through a sieve, in order to remove the husks. To produce rapid growth the chicks should be fed at daylight in the morning, and as late as they can see to eat at night. A little hemp, millet, or canary-seed given occasionally makes a nice change. Keep them well supplied with short-cut green food, such as watercress, lettuce, clover, \&c., when obtainable, and chopped raw vegetables; but do not leave any lying about to get trampled upon and go sour. After the chicks are a few days old give once a day to each twelve chicks an ounce of boiled meat that has been passed through a mincing-machine. Mix just as much food as is necessary for each meal, and give the chicks only what they will eat up readily. Should any of the chicks show signs of bowel-trouble, mix some powdered charcoal in the soft feed. Some fine, sharp grit should be sprinkled and mixed in the chickenfeed for the first week, after that the grit may be kept in a small vessel near the brooder for the chicks to help themselves. Grit is as essential to chicks as to full-grown fowls. Charcoal or charred corn is also valuable as a preventive or corrective of digestive troubles.

Mix one teaspoonful of sulphur for each thirty chicks with the soft food twice a week during dry fine weather.

See that they have plenty of fresh clean water. Have the drinkingvessel thoroughly clean, and never on any account leave the water in the sun.

The following is a good food for chicks: Mix equal parts Indian corn, barley, and oats (all ground), and add a small quantity of bran; make the whole into bread by using sour milk, and bake; then crumble and make to proper consistency with scalded milk.

Do not allow chickens and old fowls to roost together, as it tends to stunt the growth of the young birds.

\section{Drink and Food Troughs for Chickens.}

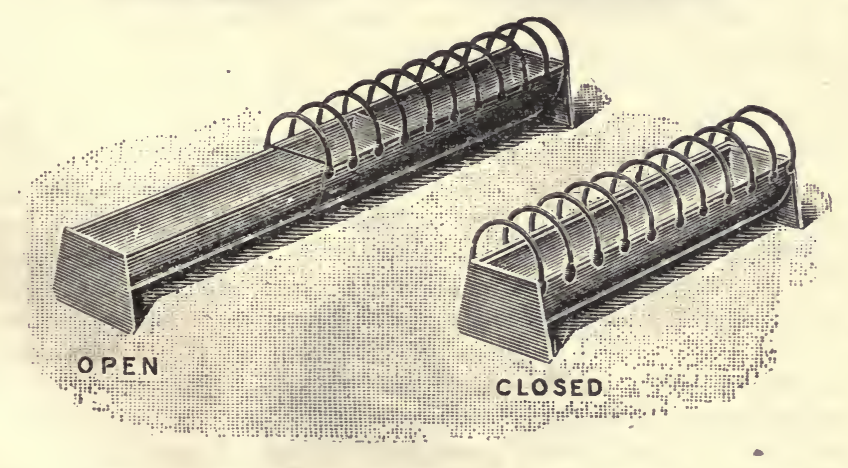

This illustration shows an excellent food-trough for chickens. "Open" shows the trough drawn out so that it may be filled with the food; "closed" shows the trough pushed in, the arched wires preventing the chickens from getting into the trough and spoiling or wasting the food. It is made of zinc, and easily cleaned. 


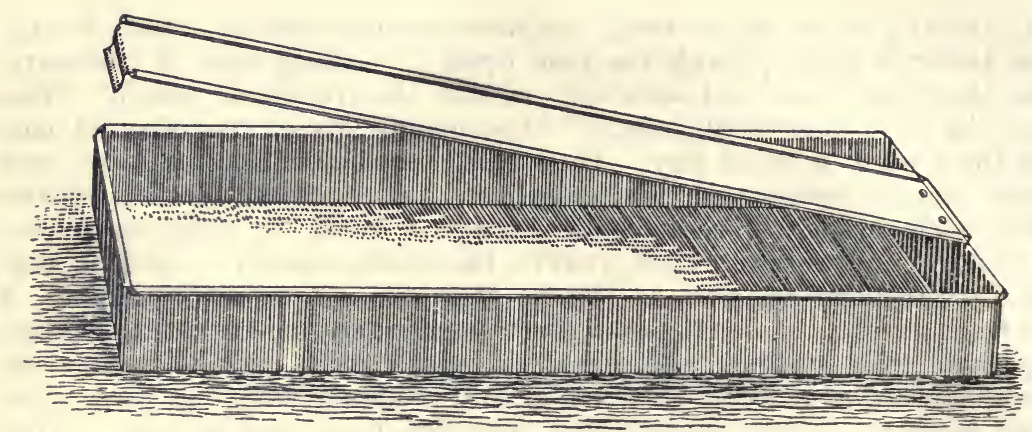

This can be used for either water or food for young chicks. The design is original, and will appeal to all poultry-breeders. Size : 18 in. long, $4 \frac{1}{2}$ in. wide, $1 \frac{1}{2}$ in. high. When the band through the centre is closed it prevents chicks from getting wet, if the trough is used for drinking purposes; if for food, the birds can only get their heads between the band and the side of the trough, and thus the food is not trampled upon and wasted. The vessel can also be easily cleaned, which is important.

Earthenware Drinking-fountain for Chickens.
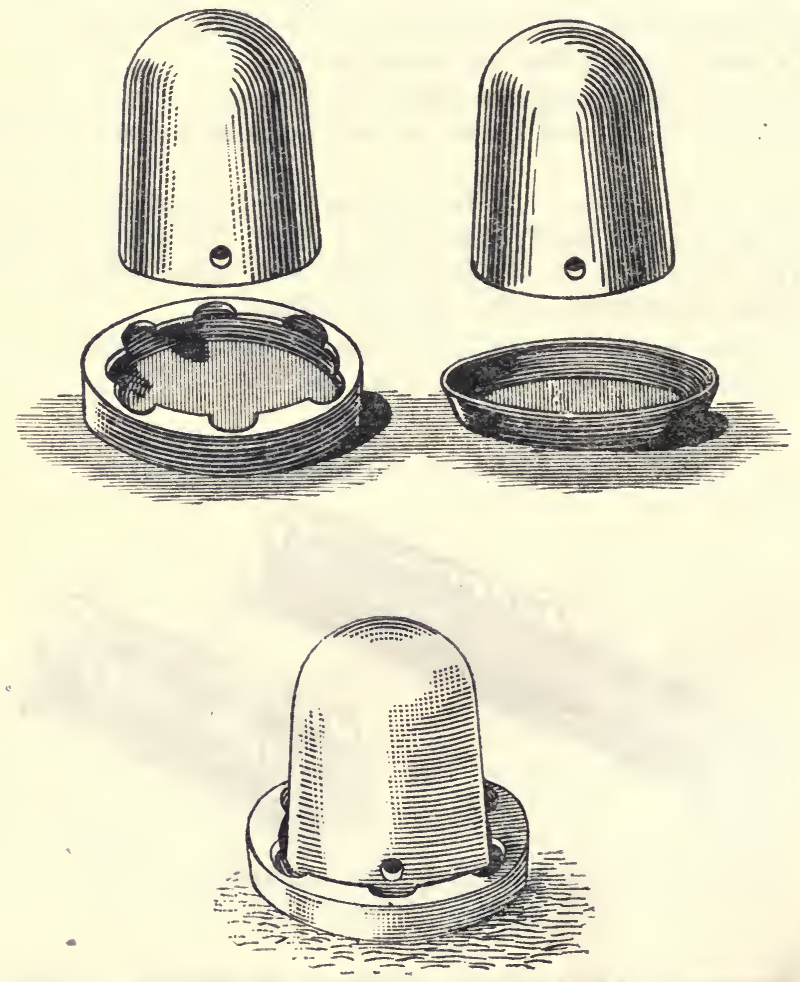

Made at Milton, New Zealand; strongly recommended. 


\section{CROSSBREDS.}

For those who are partial to crosses the following are considered the best: For table purposes, Indian Game-Dorking, Indian Game-Lang. shan, Indian Game-Houdan, and Indian Game-Orpington; Old English Game also can be used with great advantage for producing table poultry. For laying and general purposes, Leghorn-Plymouth Rock, Leghorn-Houdan, Houdan-Wyandotte, Leghorn-Orpington, and Leghorn-Wyandotte.

In all crosses use a male of the breed first named.

\section{Breeding Crossbreds.}

It is necessary to use a male of a different breed each year for at least three years in succession when crossing fowls, or they will quickly become mongrelised. Example: First year, Plymouth Rock; second year, Orpington; third year, Wyandotte; then the Plymouth Rock may be used again, and so on.

Never breed from a crossbred male.

\section{RISKS OF INBREEDING.}

It is frequently asked whether there is any harm in breeding from a cockerel and pullet that have been hatched from the same sittings of eggs. Breeding from a full brother and sister is, of course, wrong, but the probability of such a close relationship between two birds from the same sitting is very remote, the chances being about 30 to 1 . Where eggs are obtained from the Government stations the chances are still more remote, as three or four unrelated pens of birds are usually kept at each station, and eggs are selected in order to minimise as far as possible the chances of inbreeding.

\section{BEST LAYERS.}

The best laying-hens are the most active-those that will do the most scratching in the garden if given an opportunity. They are the first off the perch in the morning, and last on at night. They have generally small heads and bright eyes; select these to breed from. Those that have large heads and overhanging eyebrows will be found loitering about waiting to be fed; relegate such to the table without delay. Long beaks and long narrow heads denote a poor constitution.

A good method of discovering bad layers is to make occasional visits to the fowlhouse at night; lift each bird from the perch, those that are found above the average weight of their breed should be culled out and sent to the market, as they will almost invariably prove to be drones. Good layers will never be found very fat.

Assuming that sufficient food is given, those found to be very light, with shrivelled comb, should also be discarded-they are wasters.

The laying of each bird can be exactly ascertained by the use of trapnests. These appliances are inexpensive, and can be made by any one possessed of a little ingenuity. Both the trap-nests which are illustrated are efficient; their working is explained over the respective figures. Trap-nests also enable hens to be identified which lay badly shaped, double-yolked, or infertile eggs. 


\section{Mr. J. Rose's Trap-Nest.}

The bird after entering the nest steps on the trigger, which, working from the hinge, presses down the wire CC, drawing in the spring or catch $\mathrm{B}$ and allowing the door to drop.

The block or sill on which the door drops should be covered with leather or felt to deaden the noise.

When the door is raised the trap sets itself automatically.

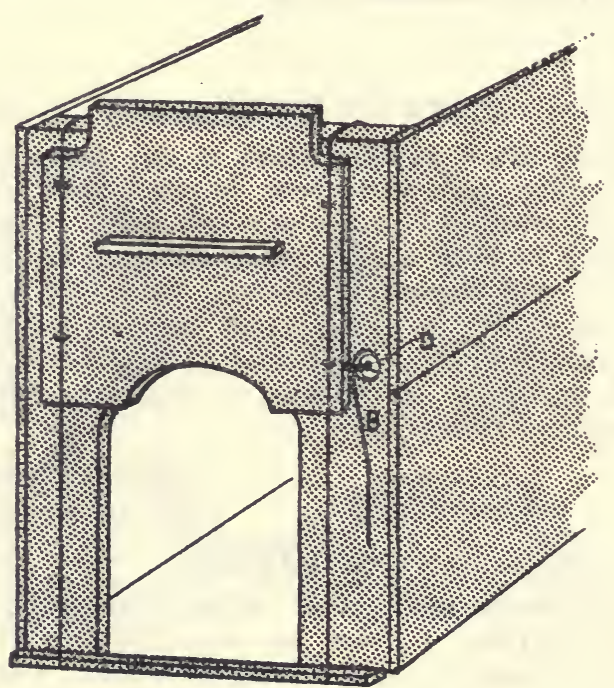

ROSE'S TRAP-NEST.

1. Exterior view : Showing the two wire uprights which act as door-guides; and the sliding door resting by means of a projecting nail $\mathrm{D}$ on the spring or catch B. The catch is made of light springy wire, bent as shown. 

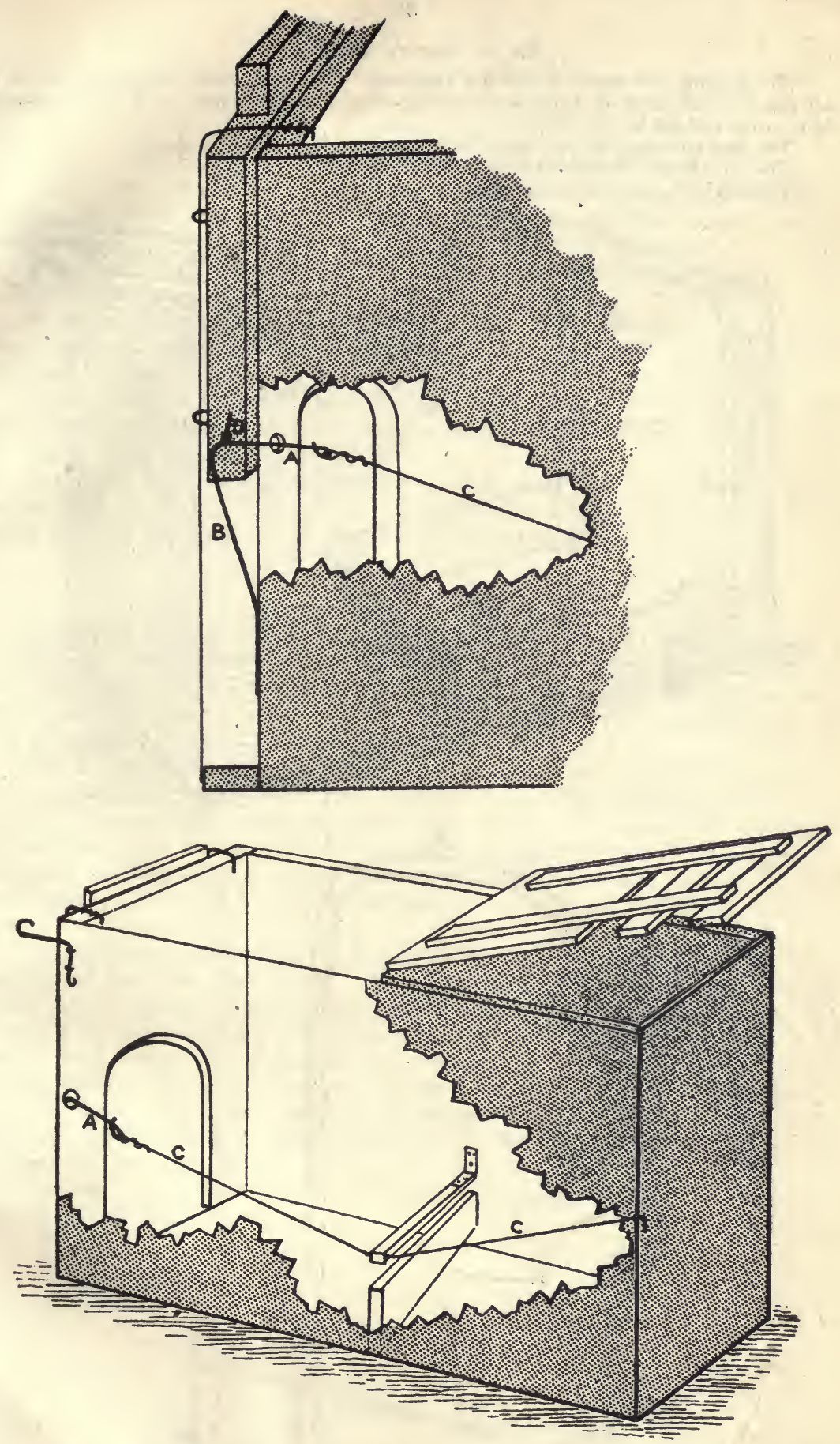

Rose's TRAP-NEST.

2 and 3. Interior view : Showing (A) continuation of spring or catch $B$ attached to a lighter wire CC, which is carried through or under the otherwise free end cf the strip of wood forming the trigger, and on to the farther end of the nest, where it is made fast. The other end of the trigger is attached to the side of the nest by a hinge.

2-Poultry. 
Mr. A. Grant's Trap-nest.

The sliding-coor works inside the trap-nest. The door-catch and trigger, A, B, C, are made of one piece of strong steel fencing-wire, bent as shown. At $\mathrm{D}$ a strip of wood $1 \frac{1}{2}$ in. wide is fixed to the wires.

The hen entering the nest steps on the wood D, releasing the door.

The sill should be covered with leather or felt.

The trap is set by lifting the door.
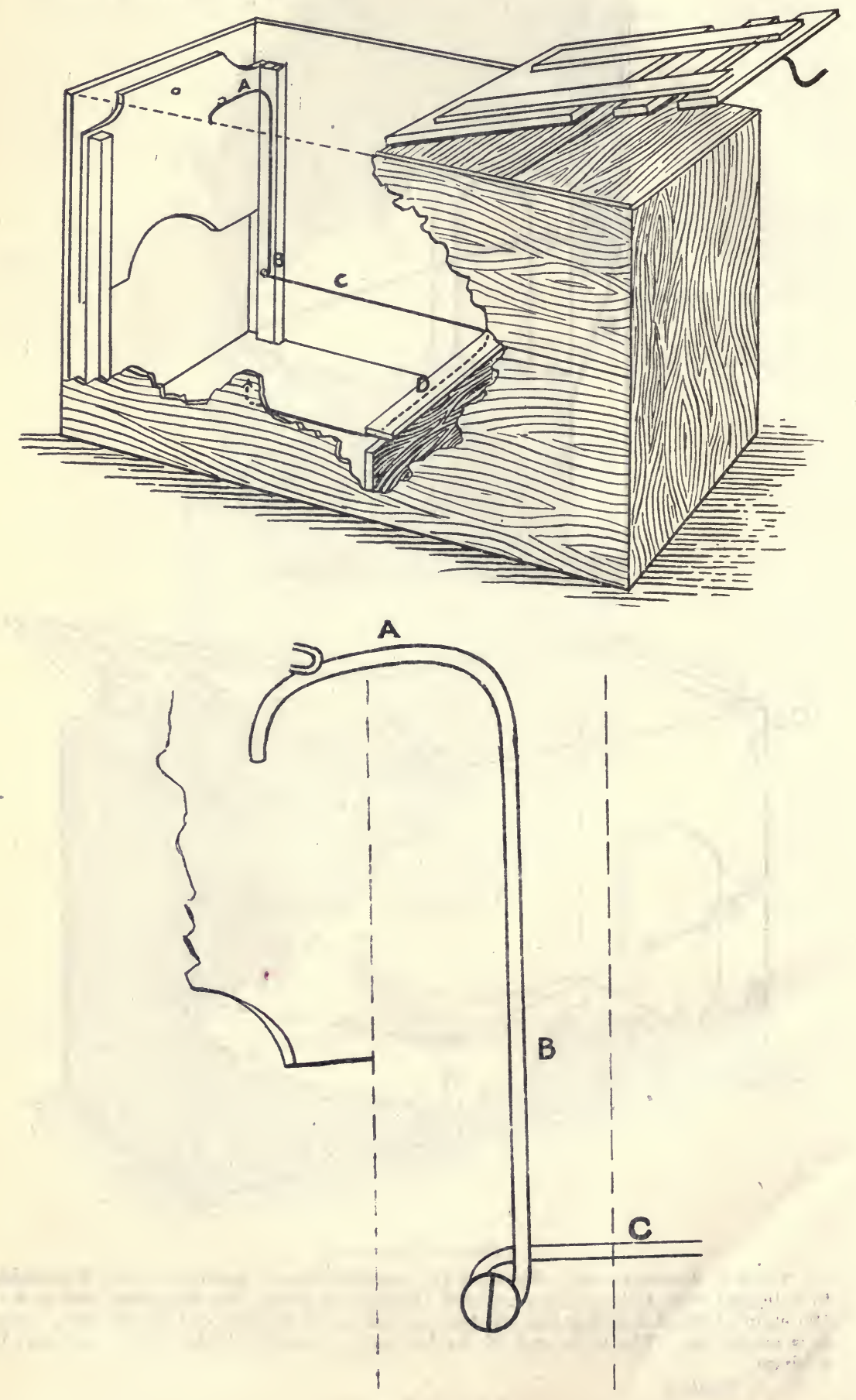


\section{GET RID OF OLD STOCK AND COCKERELS.}

It is more profitable to sell hens at the end of the second period of laying for what they will fetch than to keep them another season, during which the eggs obtained will seldom pay for the food consumed.

See the instructions under the heading of "Fattening Fowls," and act accordingly.

Cockerels should not be kept longer than five months; if properly fed they are at their best at that age, and to keep them till they are ten or twelve months old spells loss.

Remember, it costs 1 d. per week per head to feed fowls, and the only way to make a profit out of the birds sold for table use is to market them at the age advised.

Send the birds to the consumers in good condition, and there will be no lack of demand. The public will not object to pay a good price for a good article, but they resent paying a high price for a "scrag."

\section{EGG-EATERS.}

Should you have any egg-eaters among your flock, carry with you a china egg, and every time you go near the birds throw the dummy egg to the ground. The culprits will rush at and try to break the egg; after making several attempts, and failing, they will generally give up the practice.

The editor of an American poultry journal states that the best remedy for egg-eating is to give a free supply of eggs or egg-shells for a few days. This remedy, he says, never fails. Obtain a basket of fresh eggshells from your baker and throw them to the fowls whole; give them all they can eat and keep a supply before them for some days, and the trouble will cease. There is a pile of testimony, he says, to the success of this cure.

As, however, prevention is better than cure, have always a plentiful supply of lime for your hens. It is the want of lime to form the eggshell that induces the pernicious habit, as the hens lay soft-shelled eggs, which get easily broken. Once the hens taste an egg, they soon learn to break and eat a hard-shelled one. Scatter grain among hay, straw, leaves, pine-needles, \&c. ; compel the birds to exercise, and provide plenty of nest-boxes, darkened, and half-filled with straw-chaff. It is a good plan to have a few nest-eggs lying around the runs also. All these help to prevent the bad habit.

The use of a safety nest, as figured, will secure the eggs from injury by egg-eating hens.

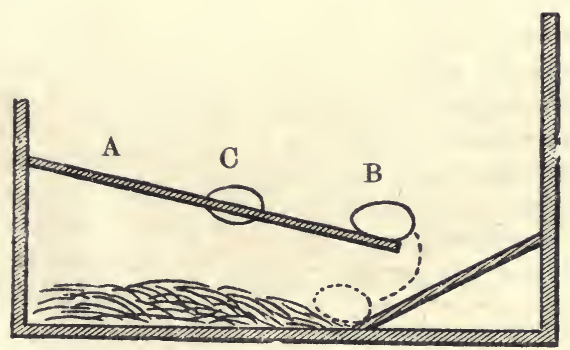

SAFETY NEST

Figure $\mathrm{A}$ is an inclined board, and should be covered with carpet or similar material; matting would be better, and tarred felt best of all. The egg, as in Figure C, is a china one, cemented half-way through the board. B is the egg rolling down to the straw on the bottom. 


\section{KEEPING A RECORD.}

Many people are under the impression that the eggs their hens lay cost about 3d. each. Keep a record on a sheet as shown herewith, and see how quickly the opinion will be changed for a more favourable one. The record will also show the profit there is in the business; the eggs may be taken at the moderate average price of 1s. per dozen all the year round.

Number of Hens ............. Breed :............ Month:.

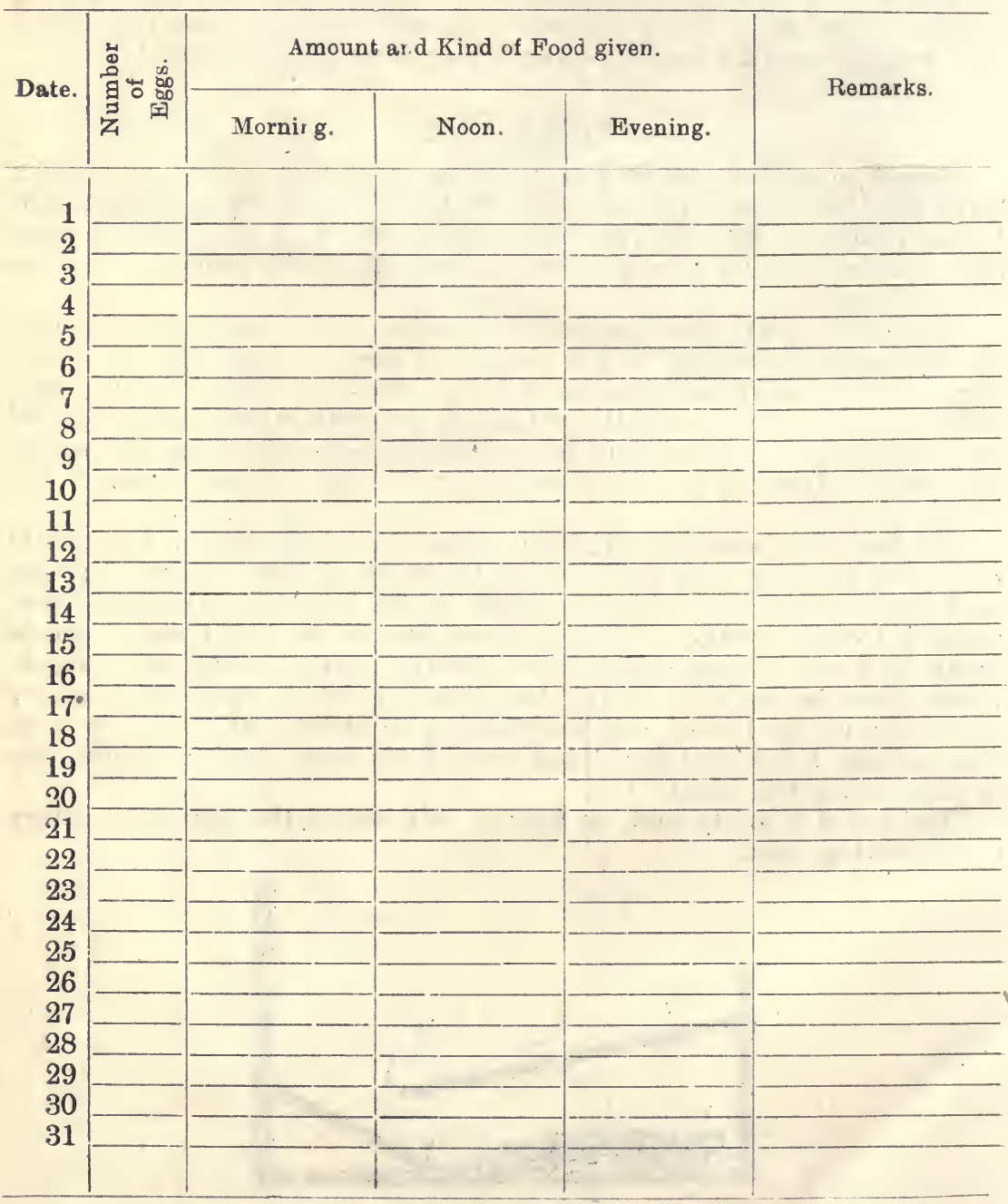




\section{WHY EGGS FAIL TO HATCH.}

Too many hens with a cock bird will result in a large number of infertile eggs or weakly chickens, and the same result may follow if the hens are too few. A great deal depends on the breed and vigour of the male bird. The best results will generally be obtained by running eight hens with one rooster of the utility breeds, such as Orpingtons, Wyandottes, Plymouth Rocks, \&c., and ten hens with one rooster of the lighter breeds-Minorcas, Leghorns, \&c.

Another cause of infertile eggs is owing to the cock bird not getting sufficient food. Very frequently he will wait until the hens are all fed before helping himself, and if there is not enough he will lose condition. It is often necessary to feed the rooster away from the hens.

Eggs from abnormally fat hens seldom hatch; the chickens die in the shell, or those that do hatch seldom live long. Overfeeding or giving fattening food to birds that are intended for breeding from should be avoided. Eggs from a lazy, sleepy hen hatch late; therefore breed from the most active hens. Dorkings, Brahmas, and Cochins-in fact, all the heavy breeds-need very careful feeding, as they put on fat quickly. Examine the condition of the birds when they are on the perch at night.

Persons who obtain eggs for setting and get poor results almost invariably blame the eggs. This is not by any means fair. Not a few hens are unsuitable for hatching; with some the temperature is too low, whilst with others it is too high; there are others, again, that sit too close, not giving the egg sufficient time to cool down.

Again, eggs are often rendered useless for hatching purposes by rough usage after they have been handed over by the postal officers to the purchaser's messenger.

Lastly, eggs often fail to hatch because some of the directions given under the heading of "Management of Sitting-hens" are neglected.

\section{FERTILITY OF EGGS.}

A few words as to infertile eggs will not be out of place. By the term "infertile" is meant an egg that has never been impregnated by the male germ, and consequently cannot possibly hatch. The germ must be communicated ere the egg is formed, and the egg is meant to be its protecting envelope. The effect of heat upon an egg is to dry up the contents and reduce them to a smaller compass. An infertile egg does not go rotten-a fact not generally known. Without death there can be no decay, and there cannot be death unless there has been life. Absence of a fertilising germ means that the contents of an egg are inert or lifeless, and will not become rotten. On the other hand, when there has been life, and this life has died, all the elements of decay are within the shell, and that which would have been its strength becomes its weakness. The only exception is: when the egg has been produced by a liseased hen the dead embryo (or, if the chick has been more or less formed, the dead chick) begins to decay, and soon the whole contents are a mass of corruption. This fact needs explanation, as many persons have erroneous ideas thereon. We have known people who have purchased eggs say (in a tone which indicated that they thought they had been cheated) that the eggs were actually rotten, whereas the fact of their being rotten proves that they were, at all events, fertile, the probability being that the, failure to hatch was due to want of proper care on the purcliaser's part. 


\section{DURATION OF THE MALE INFLUENCE.}

There is no definite rule as to the exact time it takes for the male bird's influence to affect the eggs laid, but it may be fairly accepted that eggs can be pretty safely depended upon to be fertile after a vigorous rooster has been with the hens seven days, and the eggs will continue to be fertile for the same period after his removal, always provided, of course, that the number of hens is not excessive.

\section{PACKING EGGS FOR HATCHING.}

Never nail the lid on to the box; use screws; hammering will destroy the germ.

Never put damp hay, straw, or sawdust against eggs. Never pack them, especially for a long journey, so that air is entirely excluded.

Never turn the large end down in packing, as the weight of the yolk is apt to break the air-bubble by being jarred in transit.

If you receive eggs for hatching from a distance, give them twentyfour hours' rest before putting them underneath the sitting-hen or in the incubator.

These are little precautions worth remembering.

\section{MANAGEMENT OF SITTING-HENS.}

The greatest attention should be paid to sitting-hens. In the first place, half-fill the nest-box the hen is to sit in with moist earth; beat it down pretty firmly with your hands, and make the nest so that the egg: will have a tendency to roll to the centre, or, in other words, saucershaped; then sprinkle a little lime over the earth, and a thin layer of hay, straw, or pine-needles.

Sprinkle the hen with carbolic powder or flour of sulphur, and see that the powder reaches the skin; this is to destroy the vermin that the bird is almost sure to be infested with.

In the evening place her on a few dummy eggs until satisfied she will sit steadily : she is more likely to do so if the nest is slightly darkened.

Sitting-hens should be kept away from the general flock, and should have ample hard corn, meat, bread, and hemp-seed put in a convenient place, so that they can obtain what they want on leaving the nest. Hard, sharp grit must be supplied, and plenty of fresh water should be kept in the shade ready for their use. Have a dust-bath available in a dry place where the sun can get at it.

The number of eggs to put under a hen depends upon her size, but it is better to put too few than too many; twelve eggs are enough for most hens.

Mark the large end of the eggs with the date they are placed under the hen; if marked in any other place it will interfere with the testing of the eggs.

When a hen is set in a dry place, the skin of the egg just underneath the shell becomes so dry and tough that the chick cannot cut through it, and consequently dies in the shell. Should a hen insist on sitting in a dry place, it will be necessary to moisten the eggs slightly with warm water; the best plan is to dip them and let them remain in the water for about two or three seconds. This should be done once a day during the last week of incubation.

Care must be taken when lifting the hen off the nest each morning that there are no eggs under her wings. Should an egg get broken, remove it immediately; and if any portion of the broken egg is on the others, wash it off with warm water at once, as when it dries it stops the pores of the shell and prevents the air passing to the chick. 
If two or three hens are set on the same day, and a number of the eggs should be infertile, one hen may be able to take all the eggs. If the others are cooped for a few days, they will begin to lay again; or they may be used to sit.on a fresh lot of eggs.

\section{FE E I N G FOWL S.}

\section{Foods for Poultry.}

The following foods are suitable for poultry :-

Wheat, barley, oats (Sparrow-bill), maize, rice, rye, millet, buckwheat, peas, beans, linseed, vetches, hemp-seed, rape, sunflower-seed, poppy-seed, acorns (crushed and dried), potatoes, turnips, mangolds, sugar-beet, carrots, artichokes, swedes, ricemeal, wheatmeal, barleymeal, maizemeal, ryemeal, rapemeal, linseed-cake, sunflower-seed cake, poppyseed cake, malt, brewers' grains (these should have meal mixed with them; a small quantity of oilcake should be added).

Good clover hay can be used with splendid results. The hay must be steamed or soaked in hot water after being chaffed. White-clover hay is the best. This should be mixed with the soft food.

Green cut bone, lean meat, fish, fresh milk, skim-milk, buttermilk. and whey are excellent.

\section{General Directions.}

Proper feeding is absolutely essential to success. The birds must neither be underfed nor overfed; they must be fed regularly; and the food must be of good quality and sufficient variety. Damaged or poorquality grain should be avoided. No rule can be laid down as to the quantity to be given to each fowl, as some birds are great and others small eaters; the poultry-keeper must exercise his judgment. It may be taken as a general rule never to give fowls more food than they will eat up readily.

Fowls which will not stand forcing for egg-production are useless for that purpose.

The morning meal should consist of sharps, pollard, bran, boiled potatoes, bread, or meal of any description, such as buckwheat-meal, oatmeal, barleymeal, \&c. The reason for this is that the hard corn takes: a much longer time to get soaked in the crop and ground in the gizzard, while soft meal passes at once into the system, and thus gives the birds: immediate nourishment. The above should be mixed with warm water or soup, and not made sloppy. The food should be mixed so that it will break up easily, and should be placed in troughs, as if thrown to the ground the birds run over it. Should there be more than the fowls care to eat, remove it at once, or it will quickly sour and become wasted. Use a sprinkling of salt with the food, and add, twice a week, about $2 \mathrm{oz}$. of bonemeal or green cut bone for each fowl.

\section{MIXING-TROUGH.}

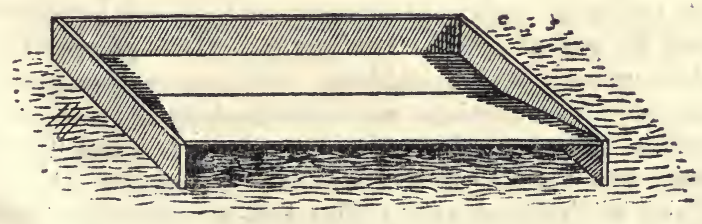

Convenient-shaped trough for mixing soft foods. 
Swing Feeding-trough

No. 1 .

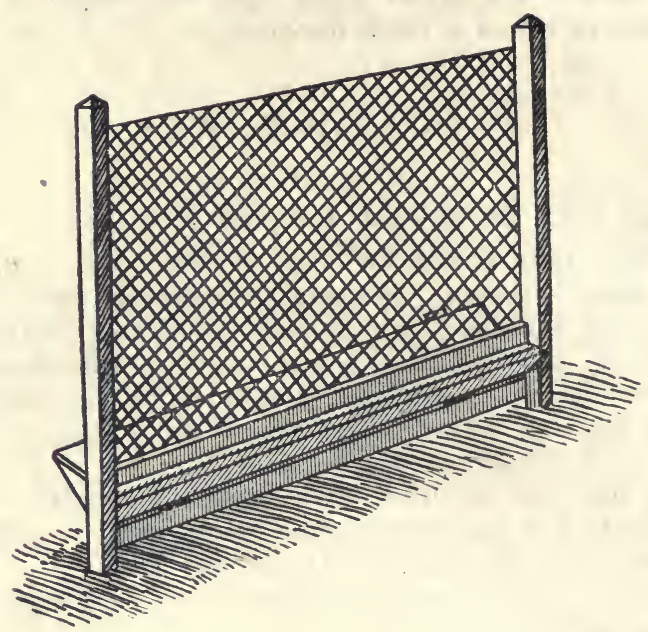

No. 2.

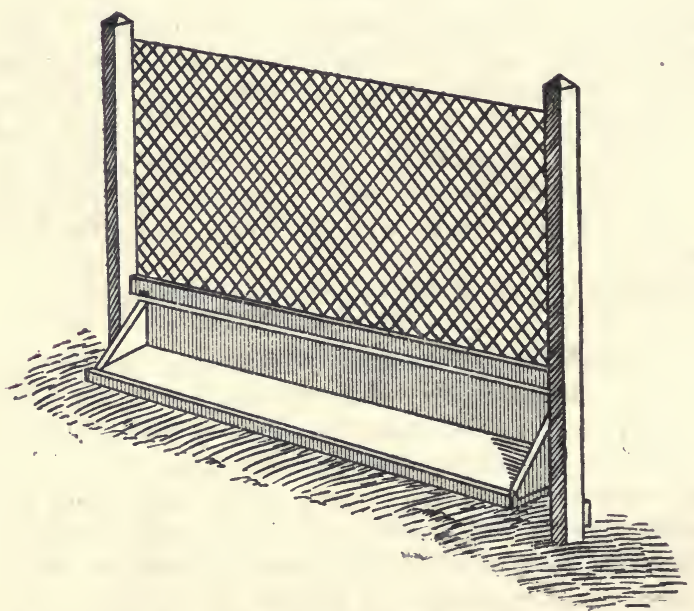

The illustrations (Nos. 1 and 2 ) show a portion of a $f_{c}$ sis l-yzd fence with swing feeding-troughs attached. This arranfement enables the atteridint to fecd the birds with soft food without entering the yard.

If fowls have an unlimited run they will only require to be fed twice a day; but if confined in a small space a light midday meal will be necessary, which should consist of table-scraps. A good thing to give is cooked meat twice a week. Arrange with your butcher to get the scraps; they can be got at a very low price. Give plesty of green food, such as short-cut grass, clover, cabbage, lettuce, watercress, \&c. Rootcrops of almost any description are excellent food for fowls, such as potatoes, mangolds, turnips, \&c.; the two latter should be cut in two and thrown down for the birds to peck at. Clover finel $\mathrm{v}$ chopped and scalded apd mixed with bran and pollard is a splendid $f_{1}$ od for laying hens. Beans and peas, cooked and thickened' with. braist, to ake an agreeable change. 
The evening meal should consist of wheat, short thick oats, Indian corn, buckwheat, and barley. The barley should be steeped in water for four or five days, and then dried in the sun, as when it is treated in that manner the birds will eat it greedily. Another way is to pour boiling water over the barley, then place a sack over the vessel and allow the grain to steam for half an hour. Other kinds of grain may be treated in the same manner. A change of food should be given as frequently as possible; onions cut into little squares and give: occasionally are very good; also sunflower-seed and hemp-seed. Indian corn is used altogether too liberally, especially in the north : many people use it week in and week out for their birds. This should not be done, as it is too heating and fattening, and should not be used more than twice a week.

A mistake to be aroided is that when foodstuffs are dear the poultry are practically starved; and not only is egg-production reduced, but birds sent to the market are almost valueless. To feed fowls insufficiently is false economy.

Overfeeding, on the other hand, is a mistaken kindness, and causes the death of many fowls and chicks. The owner soon discovers his mistake by finding a shrinkage in the number of eggs produced, many of the eggs having soft shells, some having double yolks, and others proving infertile.

Fowls must have lime in some form or another, otherwise laying hens become weakened, and often lay eggs without shells. When this occurs the eggs are apt to break before the fowls can pass them, and the fowls often die or are ruptured, being frequently found dead on the nest or underneath the perch. I would recommend every one who keeps poultry to procure a grit-mill (which can be bought from $£ 1$ upwards, according to size); with this can be crushed in a few minutes quite a large amount of oyster-shells, which will supply just what is wanted to form the egg-shells. Dry bones, which form excellent food for fowls, can be crushed in the same way. Old crockery, and even glass bottles can be crushed to supply sharp grit, which is indispensable for fowls, and acts as teeth for them to masticate their food. Keep the lime, grit, and charcoal in small boxes, so that the fowls can help themselves. A greenbone mill will soon pay for itself. One of these mills will sut green bones like shavings, to which adhere some flesh and ligaments which a hen can swallow easily. These bones can be procured from a butcher for a mere trifle, and $3 \mathrm{oz}$. or $4 \mathrm{oz}$. to each hen per week will furnish the best eggfood procurable.

\section{Douglas Mixture.}

An excellent thing for poultry, prepared as follows : $1 \mathrm{lb}$. of sulphate of iron and $1 \mathrm{oz}$. of sulphuric acid dissolved in $1 \frac{1}{2}$ gallons of water. Mix one teaspoonful to each pint of drinking-water. This should be given in cold weather and during the moulting season.

\section{LIMESTONE.}

A small piece of limestone placed in the drinking-water occasionally will be beneficial.

\section{CONSTITUENTS OF, FOODS (LEWIS WRIGHT).}

The constituents of foods may be classed as follows :-

1. Nitrogen.-The class containing nitrogen was formerly known as proteids, but is now usually called albuminoids, albumen being the chief type of the class. (The white of an egg is nearly pure albumen, mixed with much water.) There are certain vegetable principles also which contain nitrogen in the form of ammonia; these are considered as less nutritive by some writers; and classed separately;: There is no general 
agreement on this point, however; but, as most authorities class all nitrogenous compounds with the albuminoids, we shall do likewise. Fibrin in animals, gluten in grain, casein in milk, and legumin in peas belong to this group, and serve, if in proportion, as nitrogenous food. That is the great principle to bear in mind.

2. The next class consists of fats and oils (often called hydrocarbons), and is specially rich in carbon. A certain portion of fat is necessary for the healthy body itself; so necessary that unless sufficient be supplied a certain portion of albuminoids will be decomposed by the system in order to form fat. Hence fat in due proportion is absolutely necessary in order to prevent such a wasteful use of albuminoids. Besides this, fats and oils find their chief work in supplying fuel for heat and energy.

3. The next class, known as carbo-hydrates, consists of carbon (in less proportion than in fat and oils), with hydrogen and oxygen in the proportions of water. Starch, sugar, and gum are the leading compounds of this class in the vegetable world. This group also supplies fuel for heat and energy, and has plainly more or less in common with the fats and oils class. It differs, however, in this respect: it is not directly represented, as the fats group is, in the animal body itself. Carbo-hydrates are, however, capable of being decomposed into fat. Thus they save waste of albuminoid foods; in other words, a due proportion of the carbon groups, as well as of albuminoids, is necessary even for the increase or the formation of lean meat or muscle.

4. One component of regetable foods especially requires separate mention. Cellulose, the material of which tough cell-walls and woody fibre is composed, is of nearly the same chemical composition as starch. (Paper and cotton-wool are examples of cellulose.) These and kindred materials exist in a much more indigestible form, so much so that in the case of some animals it is completely indigestible. Hence for our purpose we take the harder of such constituents into a separate class, and term it "husk" or "fibre." A certain portion of these may be useful as a mechanical stimulus to the intestines, but, except in the case of ruminant animals or birds, there is no portion digested, and consequently they are of little value as food.

5. The last class is that of salts and minerals. Phosphorus and lime are needed for the bones, sulphur for the feathers chiefly" (the muscles require a small quantity also), salt for the whole range of the digestive processes, and alkaline salts to alkalinate the blood, \&c.

In addition to the five classes above mentioned, there is in all foods a very variable amount of hydrogen and oxygen in the proportions that form water, and may be classed as such, though the water-as in the case of apparently dry wheat or flour-assumes in some way a solid form and may not be water in reality.

It is on the basis of these classes that food is analysed; and the problem to be solved in feeding or in a dietary is of the simplest kind from a theoretical point of view. It is to obtain a proper proportion between the albuminoids, or nitrogenous compounds, and the heat-producing groups of fats and carbo-hydrates. A dietary or food so arranged is called a properly "balanced" ration; and if we give such a dietary in proper quantity and in digestible forms the animal or bird will be properly fed. The actual proportion in any food or any dietary is called its " nutritive ratio." Thus, a mixture of meals whose nutritive ratio is $1: 6$ means that the albuminoids therein are as one part (by weight) to six parts of fats and carbo-hydrates. But in calculating this ratio one important modification must always be made: "Fats" are much more fattening than starch or other carbo-hydrates, and are more efficient generally, because, as already noted, they are richer in carbon. In adding up the two groups, therefore, we must multiply the figure for 
fats and oils by some other figure, then we may add the product thus obtained to the carbo-hydrates, and reckon the total as one for the nutritive ratio. The precise figure to be used has caused some discussion, but the best authorities now consider that the correct figure is the equivalent of "heat" produced by the two groups. Accordingly, we must multiply the figure for fats and oils by $2 \cdot 25$ (or $2 \frac{1}{4}$ ), and we may then add them to the carbo-hydrates, and thus obtain the true nutritive ratio. It is on this basis, then, that we must deal with foods. The table herewith gives the principal materials available for poultry-feeding, showing their composition as above described. The amount of fats and oils is further shown as multiplied by $2 \frac{1}{4}$ in order that this product may be used for calculating the nutritive ratio.

The method adopted is, multiply fats and oils by $2 \frac{1}{4}$, add carbohydrates, then divide the product by the albuminoids; this will give the albuminoid, or nutritive ratio, as shown in the last column.

\begin{tabular}{|c|c|c|c|c|c|c|c|c|}
\hline Articles of Food. & 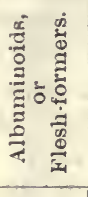 & 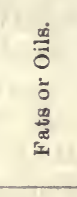 & 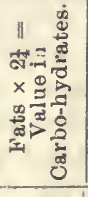 & 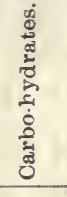 & 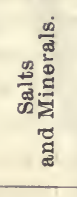 & 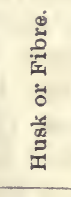 & $\begin{array}{l}\dot{\bar{\Phi}} \\
\stackrel{\Phi}{*} \\
\vec{\nabla}\end{array}$ & 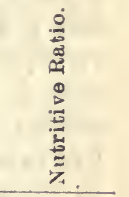 \\
\hline 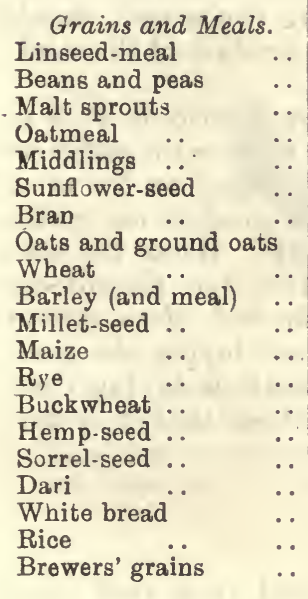 & $\begin{array}{l}32 \cdot 9 \\
24 \cdot 0 \\
23 \cdot 2 \\
18 \cdot 0 \\
16 \cdot 0 \\
16 \cdot 0 \\
15 \cdot 5 \\
15 \cdot 0 \\
12 \cdot 0 \\
12 \cdot 0 \\
11 \cdot 3 \\
10 \cdot 5 \\
10 \cdot 5 \\
10 \cdot 1 \\
10 \cdot 1 \\
6 \cdot 7 \\
9 \cdot 5 \\
8 \cdot 8 \\
6 \cdot 6 \\
5 \cdot 4\end{array}$ & $\begin{array}{r}7 \cdot 9 \\
1 \cdot 5 \\
1 \cdot 7 \\
6 \cdot 0 \\
4 \cdot 0 \\
21 \cdot 5 \\
4 \cdot 0 \\
5 \cdot 5 \\
1 \cdot 8 \\
1 \cdot 4 \\
4 \cdot 0 \\
8 \cdot 0 \\
1 \cdot 8 \\
2 \cdot 2 \\
21 \cdot 0 \\
3 \cdot 6 \\
4 \cdot 5 \\
1 \cdot 8 \\
0 \cdot 4 \\
1 \cdot 6\end{array}$ & $\begin{array}{r}17 \cdot 8 \\
3 \cdot 4 \\
3 \cdot 8 \\
13 \cdot 5 \\
9 \cdot 0 \\
48 \cdot 4 \\
9 \cdot 0 \\
12 \cdot 4 \\
4 \cdot 0 \\
3 \cdot 2 \\
9 \cdot 0 \\
18 \cdot 0 \\
4 \cdot 0 \\
5 \cdot 0 \\
47 \cdot 2 \\
8 \cdot 1 \\
10 \cdot 1 \\
4 \cdot 0 \\
0 \cdot 9 \\
3 \cdot 6\end{array}$ & $\begin{array}{l}35 \cdot 4 \\
48 \cdot 0 \\
48 \cdot 5 \\
63 \cdot 5 \\
57 \cdot 0 \\
21 \cdot 4 \\
44 \cdot 0 \\
48 \cdot 0 \\
70 \cdot 1\end{array}$ & $\begin{array}{l}5 \cdot 7 \\
2 \cdot 5 \\
5 \cdot 7 \\
2 \cdot 0 \\
\cdot \cdot 5 \\
2 \cdot 6 \\
6 \cdot 0 \\
2 \cdot 5 \\
1 \cdot 8 \\
3 \cdot 6 \\
3 \cdot 0 \\
1 \cdot 5 \\
1 \cdot 9 \\
2 \cdot 0 \\
2 \cdot 0 \\
1 \cdot 1 \\
1 \cdot 5 \\
0 \cdot 5 \\
10 \\
1 \cdot 0\end{array}$ & $\begin{array}{r}2 \cdot 3 \\
14 \cdot 0 \\
9 \cdot 4 \\
2 \cdot 5 \\
1 \cdot 7 \\
11 \cdot 0 \\
14 \cdot 0 \\
15 \cdot 5 \\
3 \cdot 3 \\
\ldots \\
\ldots \\
3 \cdot 8\end{array}$ & $\begin{array}{r}9 \cdot 2 \\
14 \cdot 0 \\
10 \cdot 2 \\
9 \cdot 0 \\
14 \cdot 0 \\
9 \cdot 5 \\
14 \cdot 0 \\
10 \cdot 0 \\
12 \cdot 0 \\
13 \cdot 0 \\
12 \cdot 3 \\
11 \cdot 0 \\
11 \cdot 6 \\
12 \cdot 6 \\
8 \cdot 0 \\
12 \cdot 7 \\
12 \cdot 5 \\
32 \cdot 5 \\
13 \cdot 0 \\
75 \cdot 7\end{array}$ & $\begin{array}{lr}1: & 1 \cdot 06 \\
1: & 2 \cdot 01 \\
1: & 2 \cdot 02 \\
1: & 4 \cdot 03 \\
1: & 4 \cdot 01 \\
1: & 4 \cdot 8 \\
1: & 3 \cdot 5 \\
1: & 4 \cdot 0 \\
1: & 6 \cdot 1 \\
1: & 4 \cdot 9 \\
1: & 6 \cdot 2 \\
1: & 8 \cdot 4 \\
1: & 7 \cdot 5 \\
1: & 6 \cdot 5 \\
1: & 9 \cdot 0 \\
1: & 10 \cdot 4 \\
1: & 8 \cdot 3 \\
1: & 6 \cdot 8 \\
1: & 12 \cdot 3 \\
1: & 3 \cdot 0\end{array}$ \\
\hline 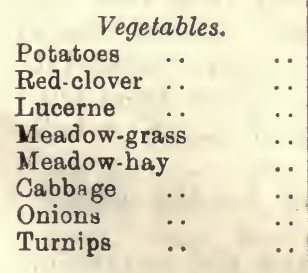 & $\begin{array}{l}6 \cdot 5 \\
5 \cdot 0 \\
5 \cdot 0 \\
3 \cdot 5 \\
8 \cdot 4 \\
2 \cdot 4 \\
1 \cdot 5 \\
0 \cdot 5\end{array}$ & $\begin{array}{l}0 \cdot 8 \\
0 \cdot 8 \\
1 \cdot 1 \\
2 \cdot 6 \\
0 \cdot 4 \\
0 \cdot 2 \\
0 \cdot 1\end{array}$ & $\begin{array}{l}1 \cdot 8 \\
1 \cdot 8 \\
2 \cdot 2 \\
5 \cdot 8 \\
0 \cdot 9 \\
0 \cdot 5 \\
0 \cdot 2\end{array}$ & $\begin{array}{r}41 \cdot 0 \\
13 \cdot 3 \\
13 \cdot 3 \\
13 \cdot 5 \\
41 \cdot 0 \\
3 \cdot 8 \\
4 \cdot 8 \\
4 \cdot 0\end{array}$ & $\begin{array}{l}2 \cdot 0 \\
2 \cdot 4 \\
2 \cdot 4 \\
2 \cdot 0 \\
6 \cdot 2 \\
1 \cdot 4 \\
0 \cdot 5 \\
1 \cdot 0\end{array}$ & $\begin{array}{r}6 \cdot 5 \\
6 \cdot 5 \\
4 \cdot 7 \\
27 \cdot 2 \\
1 \cdot 5 \\
2 \cdot 0 \\
1 \cdot 4\end{array}$ & $\begin{array}{l}50 \cdot 5 \\
72 \cdot 0 \\
72 \cdot 0 \\
75 \cdot 3 \\
14 \cdot 6 \\
90 \cdot 5 \\
91 \cdot 0 \\
93 \cdot 0\end{array}$ & $\begin{array}{ll}1: & 6 \cdot 5 \\
1: & 3 \cdot 0 \\
1: & 3 \cdot 0 \\
1: & 4 \cdot 5 \\
1: & 5 \cdot 6 \\
1: & 1 \cdot 5 \\
1: & 3 \cdot 5 \\
1: & 8 \cdot 4\end{array}$ \\
\hline $\begin{array}{ll}\quad \text { Animal Foods. } \\
\text { Dry-meat meal } & \ldots \\
\text { Flesh of fowls } & \ldots \\
\text { Horse-flesh .. } & \ldots \\
\text { Lean of beef } & \ldots \\
\text { Fresh-cut bone } & \ldots \\
\text { Dried fish .. } & \ldots \\
\text { Milk } & \ldots \\
\text { Skim-milk (separator) } \\
\text { Egg (yolk only) }\end{array}$ & $\begin{array}{r}71 \cdot 2 \\
21 \cdot 0 \\
21 \cdot 7 \\
20 \cdot 5 \\
20 \cdot 2 \\
48 \cdot 4 \\
1 \cdot 0 \\
3 \cdot 1 \\
16 \cdot 0 \\
12 \cdot 0\end{array}$ & $\begin{array}{r}13 \cdot 7 \\
3 \cdot 8 \\
2 \cdot 6 \\
3 \cdot 5 \\
26 \cdot 1 \\
11 \cdot 6 \\
3 \cdot 5 \\
0 \cdot 3 \\
30 \cdot 0 \\
2 \cdot\end{array}$ & $\begin{array}{r}30 \cdot 8 \\
8 \cdot 5 \\
5 \cdot 8 \\
7 \cdot 9 \\
58 \cdot 7 \\
26 \cdot 1 \\
7 \cdot 9 \\
0 \cdot 7 \\
67 \cdot 5 \\
4 \cdot 5\end{array}$ & $\begin{array}{l}0 \cdot 3 \\
. . \\
\ldots \\
\because . \\
\because \\
\ddot{4} \\
5 \cdot 3 \\
. .\end{array}$ & $\begin{array}{r}4 \cdot 1 \\
1 \cdot 2 \\
1 \cdot 4 \\
1 \cdot 6 \\
24 \cdot 0 \\
29 \cdot 2 \\
0 \cdot 7 \\
0 \cdot 7 \\
10 \\
1 \cdot 2\end{array}$ & $\begin{array}{l}\cdots \\
\cdots \\
\cdots \\
\cdots \\
\cdots \\
\cdots\end{array}$ & $\begin{array}{l}10 \cdot 7 \\
74 \cdot 0 \\
74 \cdot 3 \\
74 \cdot 4 \\
29 \cdot 7 \\
10 \cdot 8 \\
87 \cdot 0 \\
90 \cdot 6 \\
53 \cdot 0 \\
84 \cdot 8\end{array}$ & $\begin{array}{ll}1: & 0 \cdot 43 \\
1: & 0 \cdot 42 \\
1: & 0 \cdot 26 \\
1: & 0 \cdot 38 \\
1: & 2 \cdot 9 \\
1: & 0 \cdot 54 \\
1: & 3 \cdot 2 \\
1: & 2 \cdot 0 \\
1: & 4 \cdot 2 \\
1: & 0 \cdot 37\end{array}$ \\
\hline
\end{tabular}


In using the above table to plan a dietary we must first decide as to the proportions that should exist between the various columns, and especially as to the proper nutritive ratio between the albuminoids and the combined groups of carbo-hydrates and fats and oils. We need not trouble ourselves much about water, or husk and fibre, except in so far as, being valueless in themselves, they affect the real cost of the food; and, although we must see that there are salts enough, we'can' easily add them where deficient; this is especially necessary for young and growing stock. It' is generally held that to maintain animal life the proportion should not be less than 1:5. Some authorities consider, more specifically, that there should be about-albuminoids, 18; fats and oils, 7; carbo-hydrates, 75; which works out the same ratio almost exactly, experts differing little in detail.

A similar ratio may be adopted for poultry, but before deciding finally there are two points to consider-firstly, exercise: Cattle lead a very indolent life, as do the majority of men in a less degree. Fowls live a decidedly active life, and it is universally agreed that an active life requires a greater proportion of albuminoids. Still, we shall be quite safe in reckoning $1: 4 \frac{1}{2}$ as a proper ratio in general weathers, and in winter the same quantity of albuminoids, but an increase of carbohydrates, or, still better, of fats and oils, so as to make the ratio $1: 5$, in order to meet the demand on the system during cold weather. Such ratios, as far as the fowls or animals themselves are concerned, should be sufficient, but we have further to consider the daily product of the stock, such as milk or eggs.

Milk contains so much fat and sugar that its own ratio is $1: 3$ or $1: 3 \frac{1}{2}$, so that additional food of the ordinary $1: 5$ ratio with sufficient succulent material to supply fluid may fairly suffice. Eggs, on the other hand, contain as much albuminoids as fat, and to produce an ounce (excluding water) of such rich material is no light task. Hence the need of special food for laying-hens. Such a bird craves for albuminous food, and every breeder knows that while laying she will often devour with eagerness those giant earthworms which when not laying she generally refuses. She must get albumen if she is to continue laying eggs, and if the poultryman is alive to his interests he will see that it is provided by a properly "balanced" ration.

\section{FATTENING FOWLS.}

Fast them from twelve to twenty-four hours, and then feed them three times a day on soft food, consisting of pollard, oatmeal, barleymeal, or maizemeal, mixed with milk, to which add some rendered fat1. lb. for every fifty fowls. The fattening process will occupy from ten to twenty days. Change their food when they seem to go off it. Give boiled grain, grit, and fresh water.

When a large number of birds are to be fattened for the market a cramming-machine should be used for the purpose.

Market the birds when they are between three and five months old. You cannot hope to make a profit on birds sold for the table if you keep them nine or ten months.

To get size in the young stock separate the sexes as early as one can be distinguished from the other. A good plan is to put those intended for table purposes out in colonies of twenty-five each in movable houses until they are ready to be brought in for the fattening process.

Birds kept in confinement, and fed from a trougn with fattening food will increase from $10 \mathrm{oz}$. to $15 \mathrm{oz}$. in a fortnight; if crammed they will put on $5 \mathrm{oz}$. to $6 \mathrm{oz}$. more weight. 


\section{Cramming-MaChine.}

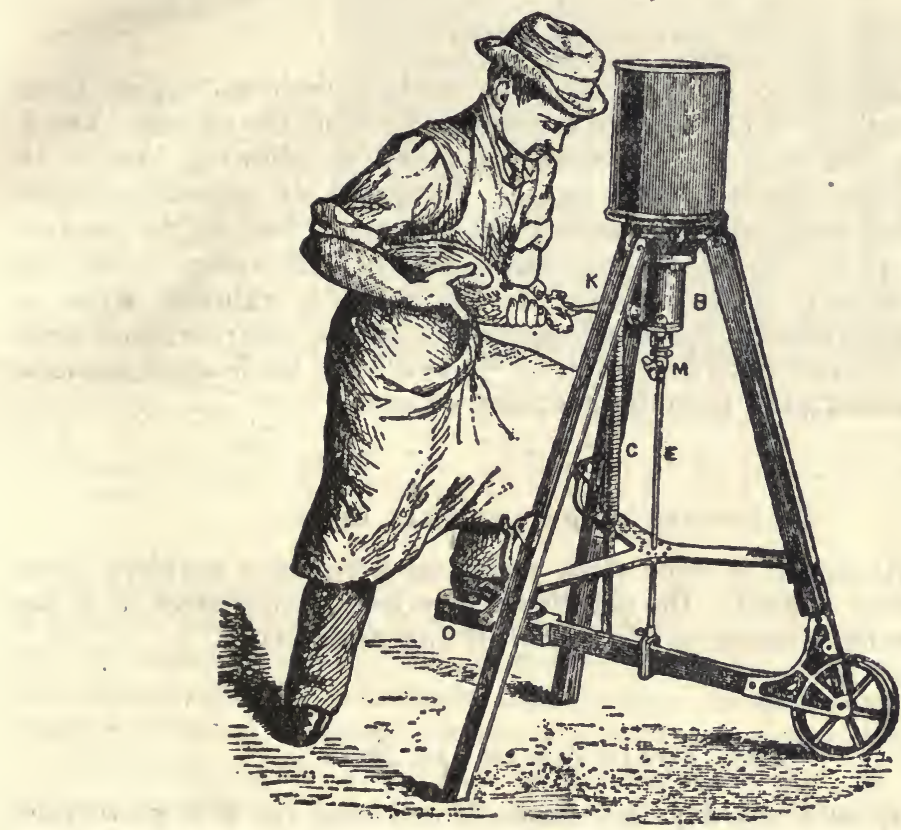

The above shows the operator at work. The flexible tube is placed in the gullet of the bird; the man's foot is placed on the lever, which, when "pressed down; forces sufficient of the thinly mixed food into the crop to fill it. The operation takes about a quarter of a minute to perform.

\section{FATTENING DUCKS, GEESE, AND TURKEYS.}

To fatten ducks or geese place them in a shed, using plenty of straw. Divide geese into flocks of ten or twelve. Ducks may be fattened in larger flocks if necessary. The process of fattening takes about twenty days. Soft food should be given in the morning, served warm, consisting of barleymeal, mixed with Indian meal, sharps, rice, and cooked meat, also boiled potatoes, scalded with milk, and with some rendered fat added. In the evening wheat, barley, oats, and maize should be given, after it has been steeped ir water. Do not fail to supply plenty of sharp grit and green food.

Turkeys must have a dry comfortable shed, and should be fed three times a day for about three or four weeks. The morning meal should consist of ground oats or barleymeal and boiled potatoes mixed with skim-milk, and give plenty of fat during the last fourteen days. Give in the evening wheat, barley, oats, and maize, after being soaked in hot. water. Supply the corn each day in rotation in the order mentioned. 


\section{DISEASES AND REMEDIES.}

\section{Causes of Disease.}

Poultry diseases are brought about by neglect, such as keeping birds in a badly ventilated or draughty building; want of cleanliness; breeding from diseased stock; careless feeding; and by allowing food to lie about and become contaminated by the droppings of unhealthy birds. A bird that dies should at once be burned, or buried deep in the ground. Should a bird die of infectious disease and be left lying about, the germs will spread in all directions. If any specially valuable birds become ill, isolate them on the first appearance of the disorder, and treat them in the manner described herein. If ordinary birds show signs of sickness, the safest plan is to destroy them at once.

\section{Prevention is Better than Cure.}

To prevent disease in your stock you must keep them perfectly clean and comfortably housed. Do not knowingly breed from stock that has had roup or other diseases or deformity of any description.

\section{Keep Fowls out of the RaIn.}

On showery and wet days the birds (if not shut in) will go to roost with damp plumage; the house becomes musty and unpleasant; the pullets do not come on to lay when they are expected, and many of the stock are seen with colds, and running at the, nostrils-a frequent forerunner of roup. Profitable poultry-keeping under such conditions is hopeless and out of the question.

\section{Limewash Your Fowlhoush.}

Twice a year have the interior of the fowlhouse and nest-boxes thoroughly limewashed or sprayed. Slosh it on and fill all the cracks and crevices, so as not to give the insects room to congregate. The mixture can be made as follows: 1 bushel lime, $1 \mathrm{lb}$. salt, a pailful of buttermilk, and add just what water is necessary.

\section{Insect Pests.}

Numerous as are the enemies from which poultry suffer, there are none that cause greater damage than insect pests. Thousands of chickens die owing to their life-blood being sucked out by parasites. The principal cause is unclean abodes, and crowding too many under one roof. Dust-baths should be provided to enable the birds to rid themselves of vermin. 
Treatment.-Press the nostrils until they are free from matter. Bathe the head and throat twice each day with a solution of vinegar and water in the proportion of one of vinegar to ten of water, or bathe in the same way with Condy's fluid. Give a teaspoonful of castor-oil and $\mathbf{1} \mathbf{g r}$. quinine pill night and morning. Birds affected should be isolated, and kept in a warm, dry shed.

The following are also good remedies :-

One-fourth teaspoonful of pepper, three-fourths ditto of milk: to be given twice a day.

A teaspoonful of sweet oil, one ditto of kerosene, four drops carbolic acid; mix, and inject a few drops into the nostrils. Apply with a small oil-can or syringe, and put a little camphorated oil on affected parts.

One tumblerful of vinegar, one-fourth ditto water, one teaspoonful cayenne pepper : mix thoroughly, and give each bird one teaspoonful three times a day.

Put half a teaspoonful of Condy's crystals into a pint bottle of water; add one dessertspoonful of the mixture to two quarts of drinking-water.

\section{Cholera.}

This is a contagious and deadly form of diarrhœea. The afiected fowls mope about; the discharge from the bowels is of a watery nature and particularly offensive. Remove all affected birds from those which appear healthy; scald out all the drinking-vessels, and give water with a few drops of laudanum; give boiled rice and a sprinkling of powdered chalk. If the case is very aggravated, give a pill made up as follows : Opium, 2 gr.; rhubarb, $3 \mathrm{gr}$.; powdered chalk, $3 \mathrm{gr}$. Give this pill once daily.

\section{Cramp.}

This is brought about through the fowls being kept in a damp place. The feet become contracted and the birds cannot stand. Remove to a warm place, rub the legs with embrocation or turpentine, and give warm food with cayenne pepper or powdered ginger.

\section{Crop-bound.}

This is a complaint that can easily be cured. It is caused very often by birds being without green food for a length of time, then feeding off long grass and hard corn, which causes the crop to swell. Get an assistant to hold the bird on its back between his knees; the operator will then hold the crop in the left hand, remove a few feathers, and with a sharp knife make a cut about $\frac{3}{4}$ in. long and remove the contents of the crop with an egg-spoon; put a couple of stitches in the crop, and place the bird in a coop for two days, and give only soft food; it will generally be all right again in that time.

\section{GaPes.}

The symptom of this complaint is continual yawning. The disease is generally confined to young chickens. It consists of small red worms in the windpipe. Extract the worms by passing a wing-feather down the throat, give a gentle turn two or three times, and then withdraw care- 
fully, when, on examining the feather, there will often be three or four worms on the end of it. Put a piece of camphor the size of a walnut in the drinking-water, replacing the camphor when fresh water is given.

Another remedy: One teaspoonful of turpentine in a pint of meal made into dough with water.

\section{LEG-WEAKNESS.}

This is an affection which attacks young birds of the heavy breeds. Parrish's chemical food is the best remedy. Give one teaspoonful to a pint of water well mixed, and reduce stimulating food.

\section{Apoplexy.}

This is chiefly caused by overfeeding; maize used frequently will bring on this deadly complaint. Hens will often die from this if chased. Administer a dose of Epsom salts, a quarter of a packet for each bird, and feed on rice and other soft food.

\section{Sneezina.}

A good remedy for fowls that sneeze, owing to a cold in the head, is to put one teaspoonful of kerosene in a pint of drinking-water.

\section{Disease of the Egg-organs.}

When a hen becomes egg-bound, pass a well-oiled feather into the rent and about the edge of the aperture; if the egg does not soon come away, hold the bird with the vent over a jug of boiling water for a few minutes. If these measures do not succeed, place the bird on its back between your knees, with your finger and thumb of the left hand outside the bird's body; push the egg carefully towards the vent until it slightly protrudes, then prick the end of the egg to liberate its contents; carefully break the egg-shell and take it away, oil the finger and pass it into the vent and make sure all the pieces of shell are taken out.

\section{Scaly Legs}

is caused by a minute parasite. Bathe the legs well three times a week with hot water, and rub on a mixture of kerosene, sulphur, and lard. The mixture should be about the consistency of paint.

Another good remedy is to use a teaspoonful of coal-oil with a cupful of lard; apply freely; a few applications will usually suffice.

Isolate affected birds from the remainder of the flock, as the disease is contagious.

\section{Eruption on Comb.}

When an eruption breaks out on a bird's comb, give half a teaspoonful of castor-oil. Rub the affected part lightly with olive-oil, in which should be mixed six drops of carbolic acid. Give the bird plenty of green food. 


\section{DUCK-RAISING.}

This is a branch of the poultry industry that is being rapidly taken up in this colony, and rightly so, as there is money in it.

It is unwise to have ducks and fowls running together. Keep them entirely separate.

Although it is not absolutely necessary to have a pond for ducks, when such is available there will be a better percentage of fertile eggs. The young birds should only have access to the pond once a week, in order that they may have a good wash. Too frequent bathing will retard growth and reduce the condition of the birds.

Ducklings should be kept in small runs, so that they can be got ready for the market as early as possible, which must be when they are from eight to twelve weeks old; if kept longer than three months old they will go into moult, and lose condition rapidly. If allowed a big range their growth will be much slower.

It is advisable to breed only white-plumaged varieties-viz., Pekin and Aylesbury. The latter breed is the most suitable for the London market, but the Pekin is hardier, and the better layer of the two.

Allow four or five ducks to each drake for breeding purposes.

The best time of the year for hatching is October and November, as the eggs are better fertilised at that time.

\section{Artificial Incubation.}

The instructions given under this heading with regard to fowl-eggs apply equally to duck-eggs.

\section{Brooding and Feeding Ducklings.}

The temperature of the brooder should be $90^{\circ}$ to $95^{\circ}$ before the ducklings are placed in it, and that heat should be maintained for the first three days. After that the temperature should be gradually reduced. If the ducklings crowd together, more heat is necessary. Give them liberty away from the brooder by degrees, as they are apt to lose their way and get chilled, which would be fatal. Should they be found huddled outside the brooder put them back under the "hover." Excepting in very cold weather, ducklings only require heat for about ten days.

Their first feed should consist of two-thirds bran mixed with oat or corn meal, to which should be added 10 per cent. hard-boiled egg and 5 per cent. small sharp grit. They must have an ample supply of water, particularly at feeding-time. Never give more food at a time than they will eat up clean. After the birds are a week old do not mix grit with their food, but keep it within easy reach of them so that they can help themselves. Ducklings should be fed every two hours the first week, 



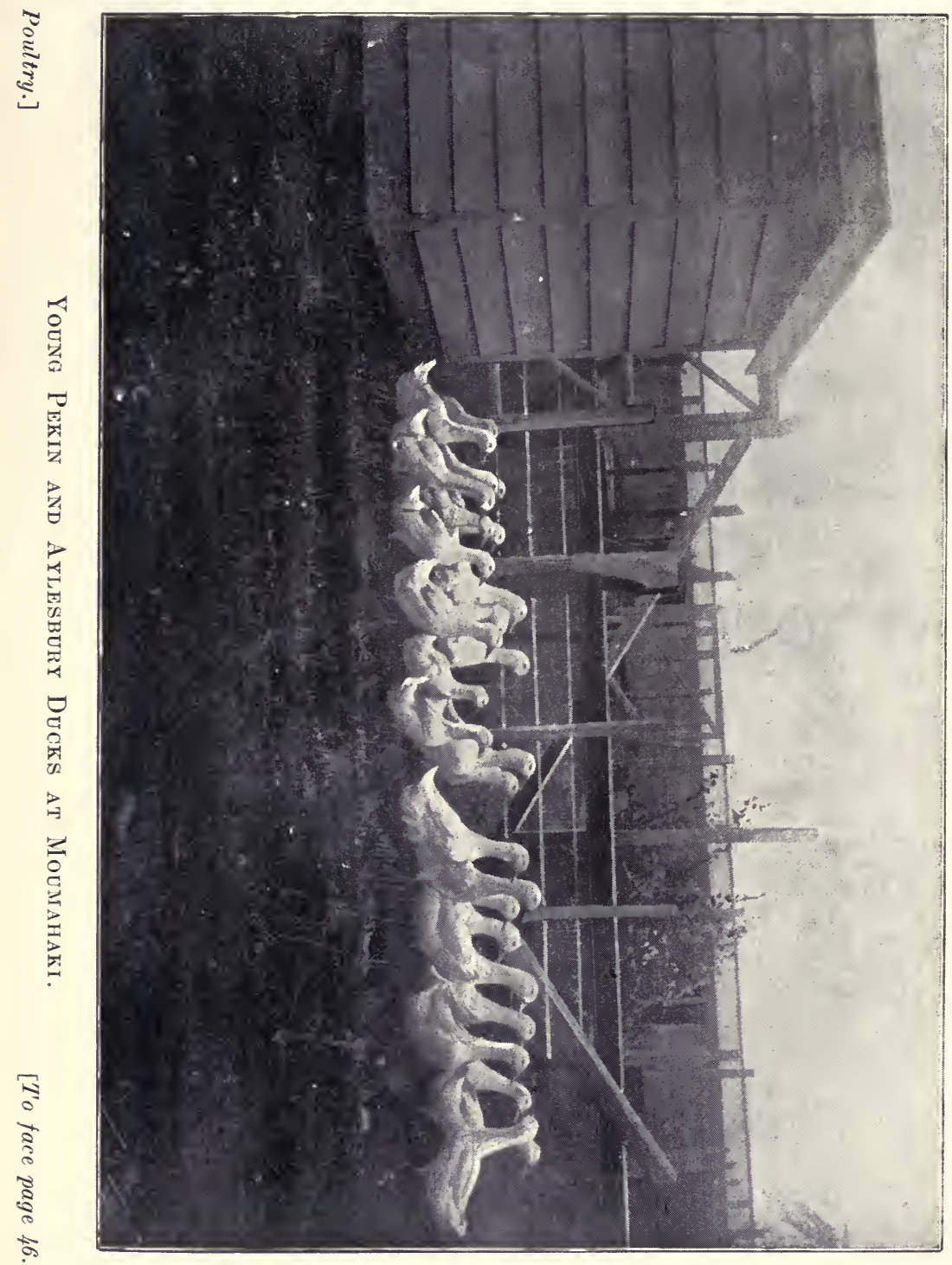





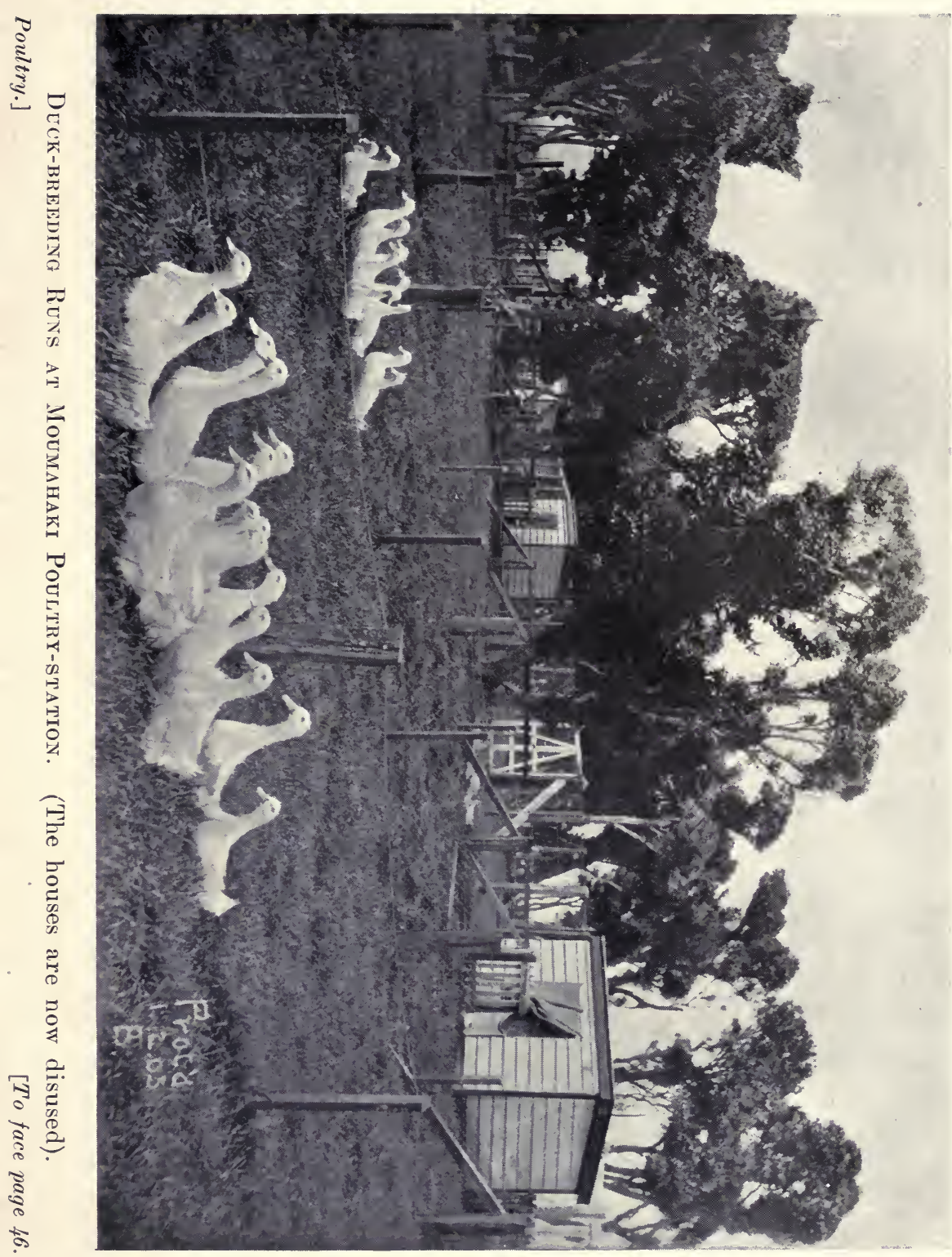


every three hours the second and third weeks, after that three times a day. At first give 2 per cent. meat (that has been passed through a mincing-machine), and increase it by about that quantity each week up to the fifth week, when about 10 per cent. of meat will be given. Provide short-cut green food at all times, and boiled potatoes, turnips, and other vegetables should be given occasionally. Ducklings should be fer from troughs. If the food is thrown to the ground for them they will trample on and waste a large quantity of it. Sharp grit and crushed oyster-shells. and also green food, are absolute necessities for ducks, young and old.

\section{Feeding Ducks.}

The following will be found an excellent mixture for stock ducks: Four parts barleymeal; three parts pollard, one part bran, and one part beanmeal; add 10 per cent. of meat three times a week. If soup is used for mixing, dispense with the meat. This mixture should be given warm, in the consistency of stiff porridge. In the evening give soaked grain. 


\section{RAISING GEESE.}

The breeding of geese can be carried on profitably, as they feed mainly on pasture. It is, however, advisable to give the old birds a little soaked grain at night in order to induce them to come home.

There are a number of varieties of geese, but the most desirable to keep are the Toulouse and the Emden. The Emden, being a purewhite colour, presents a much more attractive appearance when dressed for the table than the dark-plumaged birds, owing to the objectionable dark pin-feathers in the latter.

The average number of eggs laid is about thirty a year. The number of geese with one gander should be two or three. The best time to mate them is in their second year, and they should be dispensed with when they are ten years old.

It is better to use large hens, not geese, to incubate the eggs, giving each hen from four to six eggs. The length of time required to hatch is twenty-nine to thirty days. Sprinkle the eggs occasionally with warm water. When the birds are hatched, feed them in the morning as already described for ducklings. Keep the young birds away from the pond or stream until they are nearly feathered, but always have clean water before them to drink. 


\section{TURKEY-RAISING.}

The first and most important requirement in turkey-raising is strong, vigorous stock. The birds thrive best upon high and dry land, and especially where there is plenty of scrub. The greater the range you give them. the better; they will then to a large extent find their own living. They do not reach maturity until they are three years old, so it is quite a mistake to breed from birds under two years of age. The male should be either two or three years old; a frequent change of blood is essential.

The hens lay from twenty to thirty eggs and then become broody. The period of incubation is twenty-eight days. The chicks are very stupid at first, and it is a good plan to place two or three hen-eggs with the turkey-eggs a week after the latter have been started; the chickens will teach the young turkeys to pick up their food. Particular care must be taken not to overfeed the breeding birds, and avoid using a young gobbler and pullets of the same flock. It is not advisable to run more than eight or nine hens with a gobbler. Do not fail to keep the nest and the turkey-hen free from vermin by using insect-powder at least twice during the time she is sitting, or there will be little hope of raising the poults when hatched. Twenty-four to thirty-six hours after the chicks are hatched provide food for them as follows: Stale bread soaked in milk and squeezed dry, adding a small quantity of hard-boiled egg (the eggs should be allowed to boil from fifteen to thirty minutes), and occasionally give rice that has been boiled in milk. Oatmeal, barleymeal, and maizemeal can be given. The food must be mixed to a dry consistency. Do not forget short-cut green food, consisting of oniontops and lettuce. Meat passed through a mincing-machine, with just a little pepper in it, is beneficial. Sharp grit is necessary. Keep young turkeys longer on soft food than other chicks. Great care must be taken not to feed the young birds too much at one time, and if it can be prevented never allow the poults to get wet; a soaking is fatal to them. 


\section{“DON'TS" FOR POULTRY-KEEPERS.}

Don't fail to gather eggs twice a day.

Don't take eggs to market unless they are clean and inviting.

Don't forget that eggs are porous, and contaminating surroundings will spoil them.

Don't forget that if a brooding hen is allowed to sit on a fertilised egg for twelve hours the flavour is spoiled.

Don't forget that the sooner eggs are marketed the better.

Don't forget that the flavour of the egg is affected by the quality of the food given to hens.

Don't keep a male bird with hens that are not required to breed from.

Don't allow hens to eat decayed vegetable or animal substances.

Don't keep the water in the sun; it should be always sweet and clean.

Don't forget that sharp grit is teeth to poultry.

Don't feed poultry at irregular intervals.

Don't have filthy nest-boxes; keep them limewashed, and have clean hay, straw, shavings, or pine-needles in them.

Don't fail to have two or three nest-eggs in each nest; it goes a long way to prevent fowls eating their eggs.

Don't have perches nailed, or built in step-ladder fashion, but have them on a level 12 in. to 18 in. from the ground.

Don't forget to breed from your best layers only.

Don't fail to fill your incubator and brooder lamps daily.

Don't send to the export depots birds that are not in good condition.

Don't fail to work up a private trade if possible.

Don't fail to keep a record of the eggs laid during the year.

Don't neglect keeping fowlhouses dry, clean, and free from vermin.

Don't fail to let plenty of sunlight into your fowlhouse; have a large window facing north-east if possible.

Don't fail to keep oyster-shell or lime, and sharp grit, always before your poultry.

Don't forget that long-legged birds are seldom good layers, and as a rule are deficient in breast-meat.

Don't breed from loose-feathered birds; the tight and abundantly feathered are usually the best layers.

Don't forget that the breeding-pen must be dry to get a good percentage of fertile eggs.

Don't fail to give your birds green feed if the grass has become long and rank. 
Don't fail to grow all the green feed required if you have space.

Don't grow heavy-boned birds; it is meat that is wanted, not bone.

Don't forget that a medium-sized bird of its breed is generally the best layer; large birds are prone to fat.

Don't compel good layers to support the drones; an idle hen is never a good layer.

Don't go into the poultry business if you have to depend entirely upon hired help; do the technical part of the work yourself.

Don't waste time trying to cure persistent cases of disease.

Don't feed chicks for forty-eight to sixty hours after they are hatched; feeding too soon will cause indigestion and bowel-trouble.

Don't forget to feed chicks a little and often; the drier the food the better.

Don't keep an old hen because she has some peculiarity about her; there should be no sentiment about poultry-keeping when it is a question of making a living out of it.

By Authority: John MaCKay, Government Printer, Wellington.-1908.

$[10,000 / 12 / 07-1228+$ 


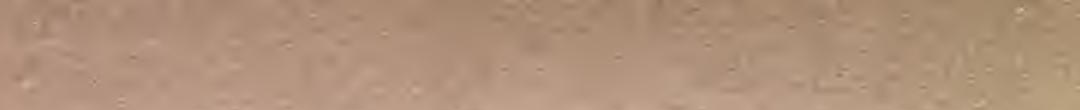

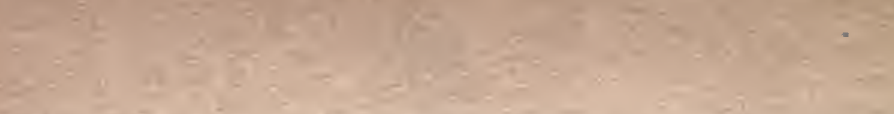

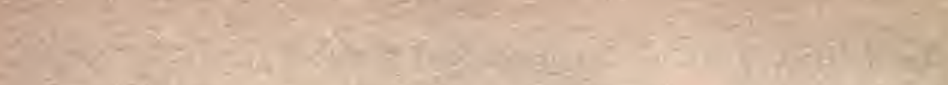

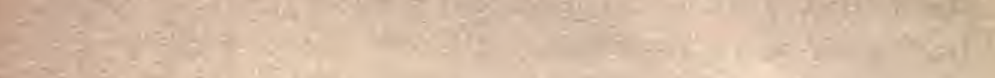

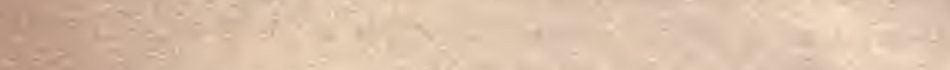

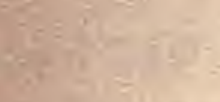

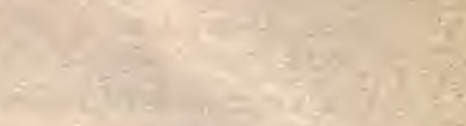

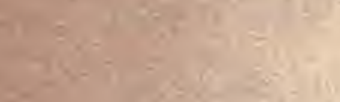

4

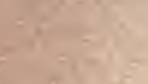

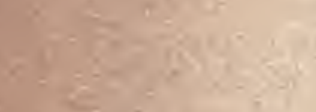

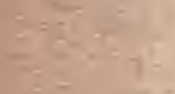

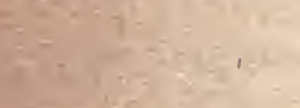

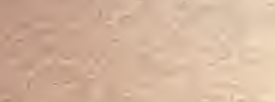

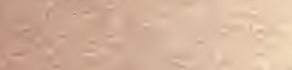

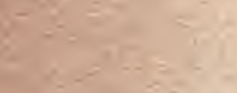

1.

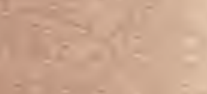

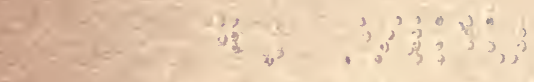

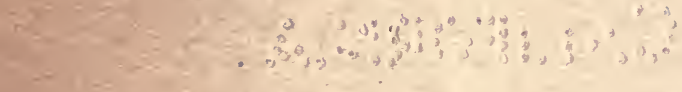

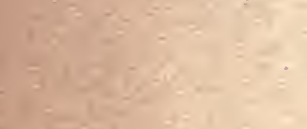

$\frac{2}{3}+5=2$

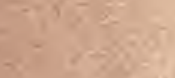

$x=\frac{1}{2}+\frac{1}{2}$

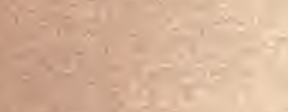

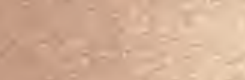

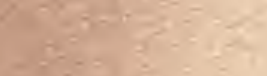

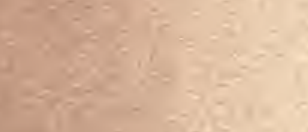

$2 x^{2}+2+2=$

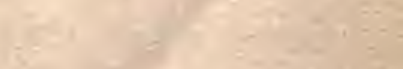

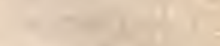

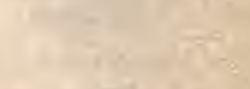

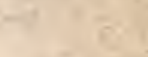

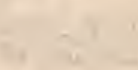

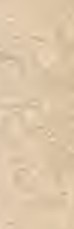

,

, (1) 


irvisible vik

Moistem with cocount milh + hold under ultru-Violet Smu landp.'Look at it with sun glasses. 







































































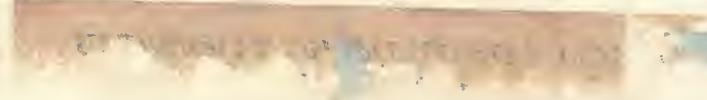




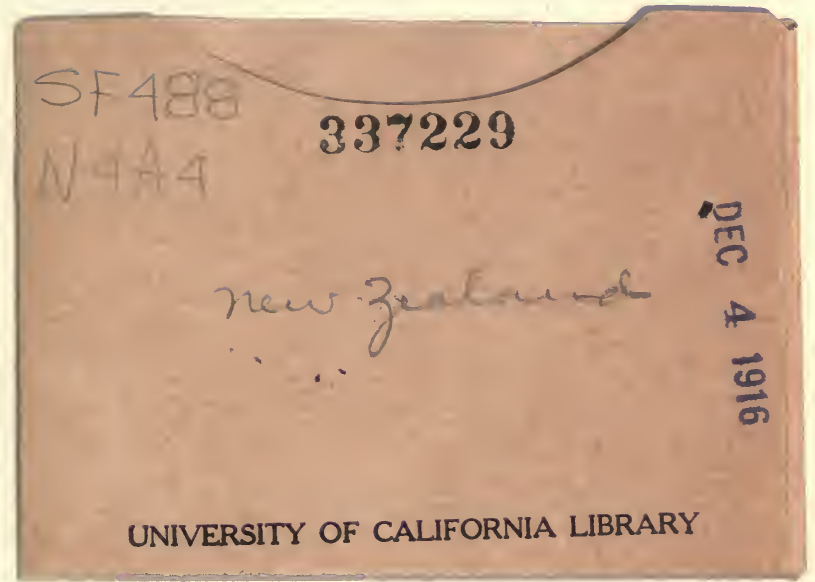


